\title{
Aetiology of Vesico Vaginal Fistula (VVF)-Observation in Patients Managed at CCBRT (Comprehensive Community Based Rehabilitation in Tanzania) Hospital, Dar es Salaam, Tanzania. January to March 2016
}

\author{
Peter Majinge1, Veronika Siebenkotten-Branca' ${ }^{2}$, Babanding Daffeh ${ }^{3}$ \\ ${ }^{1}$ Comprehensive Community Based Rehabilitation in Tanzania (CCBRT), Dar es Salaam, Tanzania \\ ${ }^{2}$ Médecins Sans Frontières (MSF), (Aerzte Ohne Grenzen-Doctors without Borders), Berlin, Germany \\ ${ }^{3}$ Serekunda General Hospital, Kanifing, The Gambia \\ Email: petjinge@gmail.com, veronikasie@web.de, babandingdaffeh@gmail.com
}

How to cite this paper: Majinge, P., Siebenkotten-Branca, V. and Daffeh, B. (2017) Aetiology of Vesico Vaginal Fistula (VVF) Observation in Patients Managed at CCBRT (Comprehensive Community Based Rehabilitation in Tanzania) Hospital, Dar es Salaam, Tanzania. January to March 2016. Open Journal of Obstetrics and Gynecology, 7, 649-677.

https://doi.org/10.4236/ojog.2017.76067

Received: October 4, 2016

Accepted: June 26, 2017

Published: June 29, 2017

Copyright (c) 2017 by authors and Scientific Research Publishing Inc. This work is licensed under the Creative Commons Attribution International License (CC BY 4.0).

http://creativecommons.org/licenses/by/4.0/

\begin{abstract}
In this manuscript the authors have studied the various causes of vesico-vaginal fistula (VVF) and described etiology, clinical characteristics, and surgical outcome of VVF patients managed at CCBRT. They show that out of $155 \mathrm{pa}$ tients 104 had surgery for VVF, 25 for stress incontinence (SI), 7 for perineal tears, 6 for recto-vaginal fistula (RVF) and 5 for other reasons, such as urethral strictures and bladder stones. They found a rate of 37 (35.58\% out of 104 patients) with definitely iatrogenic fistula and therefore support the observation also made by others that there is a shift in etiology of VVF.
\end{abstract}

\section{Keywords}

Obstetric Fistula, iatrogenic fistula, Vesico-Vaginal Fistula, Etiology, Cesarean Section

\section{Introduction}

Even though huge progress has been made in providing pregnant women with skilled birth attendants and better-equipped health facilities worldwide, there are still about 1 (to 2) million women suffering from obstetric fistula (OF) in Sub-Saha-ran Africa and South Asia [1] [2].

A fistula is defined as "an abnormal connection between an internal hollow organ and the outer epithelial layer of the body", e.g.: between the urethra, blad- 
der, ureter and/or the uterus, cervix and/or vagina [2]. The physical result of urinary incontinence has profound social and psychological consequences for the woman [3].

The term Vesico Vaginal Fistula (VVF) is most frequently used to describe an abnormal connection between organs of the pelvis, i.e.: between the urethra, bladder, ureter and the uterus, cervix and/or vagina.

Most of these OF are caused by unrelieved obstructed labour (OL), constituting an estimated $80 \%-90 \%$ of all genital fistula cases [4].

Some risk factors that can lead to OL are specific and common in countries where the incidence of genitourinary fistula (esp. VVF) is high. These risk factors include: age, stature, parity, labour duration, malnutrition, chronic anaemia, and Vitamin D deficiency that can lead to the developing of a small pelvis [5] [6].

Young women who get pregnant in their adolescence and whose pelvis has not yet finished growing are more prone to experience OL.

We performed a hospital-based retrospective, observational study from $1^{\text {st }}$ January to $31^{\text {st }}$ March 2016.

The public awareness of women's suffering from VVF is increasing; e.g.: since 2013 the UN has added a fistula awareness day: May $23^{\text {rd }}$ is "the international day to end fistula". The UN estimates that up to 2 million women in Sub-Saharan Africa, Asia, the Arab region, Latin America and the Caribbean are affected by OF, and that up to 50,000 to 100,000 new cases develop each year, in spite of the fact that fistula is almost a $100 \%$ preventable. The fact that women still suffer from OF clearly shows "that health systems are failing to meet women's essential needs" [7].

As the awareness is growing, the efforts to provide women with adequate access to appropriate medical care for OL are growing as well. This includes establishing health centres that are equipped to perform comprehensive emergency obstetric and newborn care (CEmONC), including of course caesarean sections (CS). With this, we would expect to see a corresponding decrease in VVF. Unfortunately this has not been the case. On many occasions, the person performing the emergency CS faces cases with serious complications and doesn't have the training and experience to deal with such difficult situations. This then can tend to mitigate the potential benefits of the health centres and therefore although VVF can be directly the result of OL (ischemic) it can also occur as a consequence of CS (iatrogenic).

There are obstetric and non-obstetric causes for developing a VVF.

The obstetric causes are: prolonged obstructed labour, instrumental vaginal delivery, destructive delivery, cesarean section with or without hysterectomy, traditional practices i.e.: when defibulation is necessary before delivery in women with a pharaonic circumcision (Female Genital Mutilation, FGM) or in Nigeria the so called Yankan Gishiri cutting and in rare cases, symphysiotomy is associated with uretero-vaginal fistula [8].

The non-obstetric causes include traumatic incidences such as: coitus (re- 
sponsible for many recto-vaginal fistulae), sexual violence, e.g.: forceful intercourse and/or introduction of foreign objects into the vagina, accidental trauma e.g.: falling on a stick, and female genital mutilation (FGM). Additional causes include infections such as Granulomatose, Tuberculosis, HIV, and malignancies, e.g.: advanced cervical cancer. Non-obstetric iatrogenic causes, e.g.: during pelvic surgery and radiotherapy can also cause VVF.

Genito-urinary fistulae among them VVF from non-obstetric causes occur worldwide, but obstetric fistulae occur almost entirely in the developing world. The incidence is difficult to study and the available data are mainly obtained from various hospital-based studies with the result being subject to controversy.

Adler calculated about just over 1 million women in Sub-Saharan Africa and South Asia suffering from OF [2]. As the population of women in reproductive age (15 - 49 y) in Tanzania is around 12 Million the number of women living with fistula would be between 12,000 and 19,200. This number is based on studies done by various researchers who estimate the burden of the disease in Sub-Saharan Africa being between 1 in 1000 to 1.6 in 1000 women of reproductive age [2].

The 2015 Annual Report of CCBRT states: "It is estimated that there may be as many as 21,400 women in Tanzania with untreated symptoms of obstetric fistula", and 3000 develop OF each year [9].

\section{Literature Review}

Africa has the highest maternal mortality rate (MMR) in the world, an estimated 546 deaths/100,000 live births. Sub-Saharan Africa, carries $66 \%$ of all of maternal deaths in the developing countries [10].

Obstructed labour (OL) is one of the most common causes of maternal and perinatal morbidity and mortality in developing countries. Worldwide it occurs in $4.6 \%$ of live births [11]. Those women who survive OL can face serious problems such as VVF and all its related conditions (obstructed labour injury complex).

In order to diagnose OL it is essential to correctly examine the labouring woman and to keep track of the progress of birthing with a properly filled in partograph.

The solution for the obstruction will frequently require cesarean section or an operative (assisted) delivery or in some cases even the surgical opening of the symphysis [8].

As the available data of incidence and prevalence of OF are usually based on self reporting, and personal communication instead of systematically collecting national data, the WHO can only estimate that between 50,000 and 100,000 women develop OF each year [12]. In 2013 Adler et al. reviewed 19 studies dealing with prevalence of OF in the different regions of the world. They found that the average prevalence of OF worldwide amounts to 0.29 OF per 1000 women of reproductive age. Separated by region, they found 1.60 OF in sub Saharan Africa and 1.20 OF South Asia, per 1000 women in reproductive age. The pooled inci- 
dence per 1000 recently pregnant women was 0.09 [2]. The Engender Health Fistula Care Plus and Maternal Health Task Force stated that in order to obtain more reliable data on incidence and prevalence the findings from community-based and health-system based data need to be linked. They suggested using the Demographic and Health Survey (DHS) fistula module, questionnaires in other household surveys, and the National Institutes of Health PROMIS system (nihpromise.org) [13].

In order to get more reliable data of the prevalence of OF in Sub-Saharan Africa Maheu-Giroux and colleagues collected data from of 19 countries. Their study assessed two estimates of prevalence:

1) The lifetime prevalence: they found an estimate of 3 in every 1000 women have had symptoms of obstetric fistula in their lifetime and,

2) The point prevalence: they found an estimate of 1 in every 1000 women currently having the symptoms.

More than two thirds of the women who took part in the study also reported that they had sought some kind of treatment. "Among women who sought care, almost three-quarters reported a complete remission" [14].

Biadgilign et al. analysed data from a population-based questionnaire in Ethiopia. Out of 14,070 women, aged 15 - 49 y who had previously given birth, 1.6 per 1000 experienced OF in their lifetime. 32\% of them had ever received treatment, resulting in in a prevalence of untreated fistula to be 7.2 per 1000 women. This means that out of a total population of approximately 19,800,000 women aged 15 - 49 who had previously given birth, a total burden of 142,387 women are living with untreated OF making Ethiopia one of the countries with the highest prevalence of OF. Countries like Nigeria, Kenya, Tanzania, DR Congo, Malawi, Cameroon and Benin also reported tens of thousands of women with fistula symptoms [15]. Although different approaches such as household and mixed method surveys, key informant interviews, health management information systems, as well as others were used to give some insight, none of these independently accurately captures the extent of the prevalence of fistula.

Furthermore, fistula mostly affects the poorest, most vulnerable, and powerless women and, as they are frequently so marginalized, that they can be lost to the "system" [13] [16]. Nevertheless, transparent and accurate data on incidence and prevalence of obstetric fistula are needed for planning, prevention and treatment of the affected women [17].

In Tanzania alone, there are up to 21,400 women currently living with untreated fistula and each year an estimated 3000 women develop new OF [9].

The data from the Global Fistula Map for 2015 show that the number of surgeries performed on fistula patients in Tanzania amount to approximately 800 per year [18].

According to their own annual report CCBRT performed 920 fistula surgeries at the Dar es Salaam center and their 6 regional partner facilities in 2015. This means we are losing ground at an alarming rate. Worldwide it is even more dramatic: an estimated 1 million women are currently living with this condition 
and probably significantly more than 20,000 women are developing new fistulas each year with only an average of 38,200 surgeries performed per year (76,000 registered surgeries in 50 countries in 2 years-see Global Fistula Map) it will take a long time to repair them all [18].

As VVF can also be caused by rape, in the war torn areas: i.e. in the east of the Democratic Republic of Congo (DRC) the Panzi Hospital published data in 2008 as follows:

Of 604 fistula patients, 24 (4\%) reported that their fistulas had been caused by sexual violence; of these, $5(0.8 \%)$ had developed fistulas as a direct result of forced penetration with foreign objects and/or gang rapes. Of the remaining patients, 6 had a fistula before they were raped, $9(1.5 \%)$ developed iatrogenic fistulas following inappropriate instrumentation to manage rape-induced spontaneous abortion or stillbirth, or after abdominal hysterectomy, and $4(0.66 \%)$ developed fistulas after prolonged and obstructed labour [19].

Another possible cause for OF is female genital cutting (FGM).

Browning (in 2010) and Wall explain that injuries of the urinary tract can be directly caused by FGM but in a study conducted in Ethiopia there was no significant difference in the occurrence of OF in women who had suffered from FGM Typ I and II and those who did not have a history of FGM.

However, in women who have been infibulated (type III FGM) significant tissue loss of the vulva can occur and the resulting fibrosis and scarring can lead to delay in the second stage of labour. Also when opening this small orifice during the delivery a (extended) midline episiotomy might cause a rectovaginal fistula (RVF) [20] [21].

In Tanzania the FGM prevalence rate is $10 \%$ of all women aged between 15 and 49 (and $4.7 \%$ for those aged 15 - 19), according to a 2015-2016 survey. Type II FGM was found to be the most common [22]. Therefore, as type II is the most prevalent form of FGM in Tanzania, we did not expect FGM being a major cause of the fistula patients treated at CCBRT.

In 2015 Paul Hilton in his study "Trends in the aetiology of urogenital fistula" asks the question: post-caesarean section fistula, traumatic or ischemic?

He found in East Africa that in "Tanzania it is reported that $85 \%$ of patients developing fistula now deliver in hospital, usually by caesarean section, with an increasing rate of vesicocervical and vesicouterine (probably iatrogenic) fistula". He concludes that in women who experienced OL for days and end up having a VVF after delivering a dead baby "should be described as having a 'true obstetric' or ischaemic fistula". But a woman who is in OL and taken to a health care facility in time where she is delivered from a live baby by CS and still ends up having a vesicocervical (Waaldijk Typ I) fistula can be reasonably described as having an iatrogenic injury. He asks: "But what of those women who are transferred only after considerable delay, or who undergo caesarean section for a dead baby and then develop a VVF? Or those who undergo caesarean section but then develop an urethrovaginal fistula or a midvaginal VVF or an ureterovaginal fistula? Should these lesions be looked on as 'obstetric', iatrogenic, or a combina- 
tion?" He points out that it is not always clear and easy to define an OF after a CS as only ischaemic or only iatrogenic, but more likely mostly the combination of both [23].

Washington et al. from Rwanda investigated a group of 65 women who underwent fistula surgery between April 2010 and February 2011. They found that $82 \%$ of 60 women had given birth in a healthcare facility. $48 \%$ [24] of the 65 women had a cesarean section. Among those who had been delivered by CS $29 \%$ (9 out of 31) had developed cervicovesical or uterovesical fistula whereas only 9\% (3 out of 34) who had a vaginal delivery developed this kind of fistula ( $\mathrm{p}=$ $0.04)$.

He observed that those women who had had a CS were more likely to suffer from a fistula that involved the cervix or the uterus [25]. So his observations go along what the findings of Hilton and Onsrud.

Thomas Raasen et al. investigated thoroughly in their study: "Iatrogenic genitourinary fistula. An 18-year retrospective review of 805 cases injuries" the different causes and influencing factors of iatrogenic fistula (IF) in a collective of nearly 6000 women from 11 countries [25]. He found that $13.2 \%$ of genitourinary fistula repairs were for "injuries caused by provider error". Four out of five IF developed as a result of obstetric surgeries, performed by different medical personnel (from clinical officer to specialists).

$57.4 \%$ of the 805 procedures resulting in IF were CS; $25 \%$ had undergone one or more previous laparotomies mostly CS (98\%).

Among these 805 cases 351 (43.6\%) had vesico-(utero)/-cervico-vaginal fistula (VCVFs) and were the most common, followed by ureteric injuries $(33.9 \%)$ and vault fistulas (22.5\%). Among these women, $25 \%$ had had more than one previous cesarean section.

He divides the IF into those that are "definitely", "probably" or "likely" iatrogenic (Figure 1).

Ureteric fistulas are definitely iatrogenic no matter if they occurred in obstetric or gynecological surgeries. Furthermore he points out that the delivery of a live baby by CS is rarely associated with pressure necrosis. Therefore if the baby is alive, a VCVF located between the lower segment of the uterus/cervix and the bladder gives a strong hint to an accidental bladder injury during the CS.

Vault fistulas that are seen after an emergency obstetric intervention such as hysterectomy after CS are "probably" iatrogenic.

If the baby was stillborn VCVFs following the CS are "likely" to be iatrogenic.

In those cases where the baby was stillborn he included VCVFs that were less than $3 \mathrm{~cm}$ in size and clearly located in the cervical canal into the category of likely to be iatrogenic.

Nearly all VCVFs $(352=100 \%)$ were associated with obstetric procedures $(349,99.4 \%)$, with 210 associated with a live birth and 139 associated with a stillbirth. $40.2 \%$ of women with VCVF had undergone at least one previous laparotomy.

Any one from assistant medical officer to a specialist performed procedures 


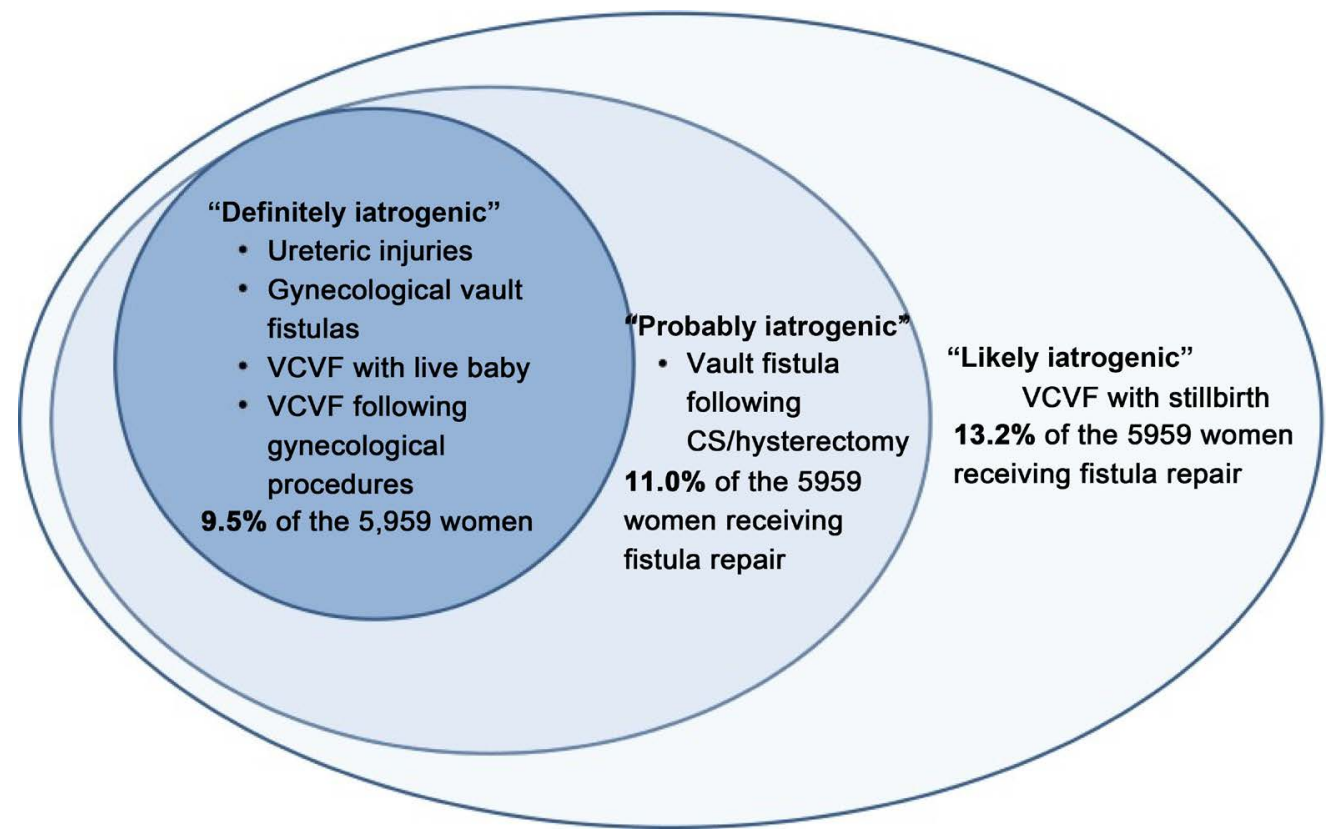

Figure 1. Raassen definition of kinds of iatrogenic fistula.

that resulted in IF. This profile is not surprising based on the human resources in the countries he investigated. As $59 \%$ of women with IF had been operated by medical officers, this reflects their high involvement in this kind of emergency surgeries.

Raassen quotes a study from Tanzania, where more than $85 \%$ of obstetric and gynecological surgeries were even performed by assistant medical officers [26] [27].

\section{Rationale}

Although there has been improvement over the last 2 decades in giving pregnant women better access to healthcare still the number of women developing VVF has not come down significantly. This suggests that there might be a shift in aetiology of these fistulas.

The results of our observations should be a contribution for the rethinking, and restructuring of obstetric care in Tanzania (e.g.: provide more and better-trained human resources, better-equipped facilities, improve ambulance services, good communication network and public awareness).

This study therefore looks into clinical characteristics and treatment outcome of all VVF cases treated at CCBRT Hospital in Dar es Salaam from $1^{\text {st }}$ January to $31^{\text {st }}$ March 2016.

\section{Objectives}

1) Describe demographic and clinical characteristics of women presenting for VVF surgery at CCBRT, Dar es Salaam between $1^{\text {st }}$ January, and $31^{\text {st }}$ March 2016 (Tables 1-3).

2) Investigate iatrogenic mitigation of the potential benefits of intervention of 
CS in women presenting for VVF surgery at CCBT, Dar es Salaam.

3) Describe the severity of VVF (using the classification of Kees Waaldijk [27] $(\text { Table } 4)^{\star}$ ) caused by Cesarean Section in patients managed at CCBRT, Dar es Salaam from $1^{\text {st }}$ January to $31^{\text {st }}$ March 2016.

4) Describe the treatment outcome of VVF patients managed at CCBRT, as to whether the fistulas were closed and the patients were not leaking urine at their discharge (Table 5).

\section{Methodology}

We performed a hospital-based retrospective, observational study from $1^{\text {st }}$ January to $31^{\text {st }}$ March 2016.

\subsection{Study Area}

This study was conducted at the VVF unit of the Comprehensive Community Based Rehabilitation in Tanzania (C.C.B.R.T) Hospital, Dar es Salaam, Tanzania. Each year about 500 to 600 women are operated for Obstetric Fistulas in the Dar es Salaam VVF unit. In 2015 CCBRT's disability hospital and 6 other regional partner hospitals repaired a total of 920 fistulas [9].

CCBRT is one of the hospitals in Tanzania that offers free surgical treatment for patients with VVF and its related injuries. It has well dedicated staffs and these include cleaners, nurses, physiotherapists, psychosocial and counselling staffs, theatre staffs and surgeons, who operate on these patients throughout the year.

The various sections of the unit include the preoperative and postoperative wards with 72 beds, OPD, physiotherapy unit and the theatre. CCBRT is also an International Federation of Gynaecology \& Obstetrics (FIGO)-accredited training centre. Since their accreditation in 2014, 10 fistula surgeons from across sub-Saharan Africa have been coached, mentored and trained in the Dar es Salaam centre. Besides the VVF department, CCBRT provides other services in various disciplines, such as orthopaedics, plastic surgery, and ophthalmology [9].

\subsection{Ethical Clearance}

Ethical Clearance was given from the Medical Advisory Committee of CCBRT.

\subsection{Study Design and Population}

We carried out an observational study of the patients from the fistula unit at CCBRT. The study population includes all women who had surgery between January $1^{\text {st }}$, and March $31^{\text {st }}, 2016$ in CCBRT. 155 women were operated during this period. 104 for VVF a as result of a delivery, 4 for VVF as a result of a total abdominal hysterectomy my (TAH) 4 for vault fistulas, 25 for Stress Incontinence (SI), 7 for perineal tears, 6 for rectovaginal fistula (RVF) and 5 for other reasons, such as urethral strictures and bladder stones. 


\subsection{Sample Size}

The sample consists of 104 women who underwent surgery for VVF, between $1^{\text {st }}$ January and $31^{\text {st }}$ March 2016 in CCBRT, Dar es Salaam, Tanzania. The patients will be followed up for at least 6 months.

\subsection{Data Collection}

The data were obtained from the patient's files in the VVF Department of CCBRT including the part of patient's history, operating reports, discharge notes and fistula cards.

\subsection{Inclusion Criteria}

We included only the 104 women who were operated on during the study period for a fistula as a result of a delivery.

\subsection{Exclusion Criteria}

Of the 155 women who had surgery done from January $1^{\text {st }}$ to March $31^{\text {st }} 2016$ in CCBRT we excluded the 41 women whose surgery was not VVF related, and the 8 women whose VVF was a result of a TAH or was a vault fistula.

\subsection{Data Entry and Analysis}

The data are summarized using descriptive statistics such as mean and range if applicable. Data are displayed in the form of tables. The results were noted as of the time of discharge from the hospital.

\section{Results}

Between $1^{\text {st }}$ January and $31^{\text {st }}$ March2016 155 women had surgical interventions at CCBRT in the Dar es Salaam Hospital. Out of these 155, those 104 who were operated for VVF were included in the study. Out of the 41 women who were excluded, 4 had had a TAH, 4 had a vault fistula, 25 had procedures done for stress incontinence, 6 had rectovaginal fistula repaired, 7 had perineal tears repaired and 5 women had other surgery such as urethral strictures treated or bladder stones removed.

Table 1. Demographic data.

\begin{tabular}{clll}
\hline Characteristic & Number of patients. & $104=100 \%$ \\
\hline Present age-Figure 2 & \multicolumn{2}{l}{ Number of patients. (\%) } & $104=100 \%$ \\
$\leq 15$ & 1 & $0.96 \%$ & \\
$16-20$ & 18 & $17.30 \%$ & \\
$21-29$ & 25 & $24.03 \%$ & \\
$30-39$ & 40 & $38.46 \%$ & \\
$\geq 40$ & 20 & $19.23 \%$ & \\
Average age: $28.48 \mathrm{y}$ & & &
\end{tabular}




\section{Continued}

\begin{tabular}{|c|c|c|}
\hline Age at which $V V F\left({ }^{*} 1\right)$ was developed-Figure 3 & & ber of pat \\
\hline$\leq 15$ & 3 & $2.88 \%$ \\
\hline $16-20$ & 28 & $26.92 \%$ \\
\hline $21-29$ & 25 & $25.00 \%$ \\
\hline $30-39$ & 34 & $31.73 \%$ \\
\hline$\leq 40$ & 6 & $5.77 \%$ \\
\hline No data available & 8 & $7.69 \%$ \\
\hline
\end{tabular}

Average age: $27.19 \mathrm{y}$

Duration of VVF in months-Figure 4

$$
\leq 3
$$$$
03-12
$$$$
13-36
$$$$
37-60
$$$$
\geq 61
$$

No data available

Average duration: 12.81 months

\section{Marital Status}

Single

Married

Separated

Divorced

Widow

No data available

Educational level of patient

$$
\begin{aligned}
& \text { No formal education } \\
& \text { Primary education }
\end{aligned}
$$
(up to standard (=STD) VII) ( $\left.{ }^{2}\right)$
Number of patients. (\%)

$104=100 \%$

$$
14 \quad 13.46 \%
$$

$41 \quad 39.42 \%$

$17 \quad 16.34 \%$

$4 \quad 3.85 \%$

$20 \quad 19.23 \%$

$8 \quad 7.69 \%$
$9 \quad 8.65 \%$

$66 \quad 63.46 \%$

$18 \quad 17.30 \%$

$2 \quad 1.92 \%$

0

$9 \quad 8.65 \%$

Number of patients. (\%)

$104=100 \%$
$31 \quad 29.80 \%$
$61 \quad 58.65 \%$
$(61=100 \%)$
STD $25 \quad 68.56 \%$ of $61 / 4.80 \%$ of 104
STD $32 \quad 3.28 \%$ of $61 / \quad 1.96 \%$ of 104
STD $4 \quad 14 \quad 22.95 \%$ of $61 / \quad 13.46 \%$ of 104
STD $52 \quad 3.28 \%$ of $61 / \quad 1.96 \%$ of 104
STD $6 \quad 3 \quad 4.92 \%$ of $61 / \quad 2.88 \%$ of 104
STD $7 \quad 35 \quad 57.38 \%$ of $61 / 33.65 \%$ of 104

Beyond standard VII

STD 8

0

STD 9 


\section{Continued}

\begin{tabular}{|c|c|c|c|}
\hline STD 10 & \multicolumn{2}{|l|}{1} & $0.96 \%$ of 104 \\
\hline Higher & \multicolumn{2}{|l|}{1} & $0.96 \%$ of 104 \\
\hline No data available & \multicolumn{2}{|l|}{10} & $8.65 \%$ of 104 \\
\hline HIV status & \multicolumn{2}{|c|}{ Number of patients. (\%) } & $104=100 \%$ \\
\hline Negative & 91 & $87.50 \%$ & \\
\hline Positive & 6 & $5.77 \%$ & \\
\hline No data available & 7 & $6.73 \%$ & \\
\hline Height of patient-Figure 5 & \multicolumn{2}{|c|}{ Number of patients. (\%) } & $104=100 \%$ \\
\hline $130-140$ & 11 & $10.57 \%$ & \\
\hline $141-150$ & 36 & $34.61 \%$ & \\
\hline $151-160$ & 27 & $25.97 \%$ & \\
\hline$\geq 161$ & 5 & $4.80 \%$ & \\
\hline No data available & 25 & $24.03 \%$ & \\
\hline \multicolumn{4}{|l|}{ Average height: $150.49 \mathrm{~cm}$} \\
\hline Weight of patient-Figure 6 & \multicolumn{2}{|c|}{ Number of patients. (\%) } & $104=100 \%$ \\
\hline$\leq 40$ & 15 & $14.42 \%$ & \\
\hline $41-50$ & 27 & $25.97 \%$ & \\
\hline$>51$ & 47 & $45.19 \%$ & \\
\hline No data available & 15 & $14.42 \%$ & \\
\hline
\end{tabular}

\section{Average weight: $48.13 \mathrm{~kg}$}

- $18.26 \%$ of 104 women were 20 years and younger (up to 20 years old); $-52.88 \%$ had been suffering from the fistula one year or less when they came for treatment to CCBRT $\left({ }^{\star} 3\right)$; - The women's average height was 150, $49 \mathrm{~cm}$; Table Legend: $\left({ }^{\star} 1\right)$ VVF = Vesico Vagina Fistula; $\left({ }^{\star} 2\right)$ STD = Standard Level of education; $\left({ }^{*} 3\right)$ CCBRT $=$ Comprehensive Community Based Rehabilitation in Tanzania (C.C.B.R.T) Hospital, Dar es Salaam, Tanzania.

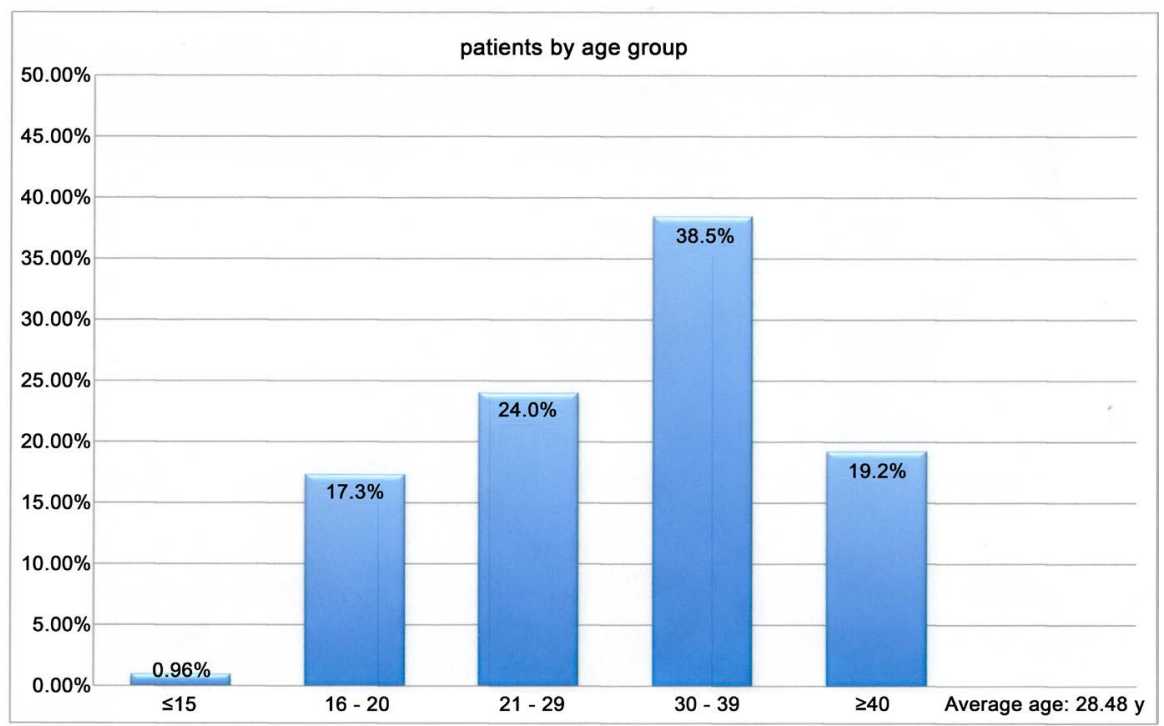

Figure 2. Patients by age group. 


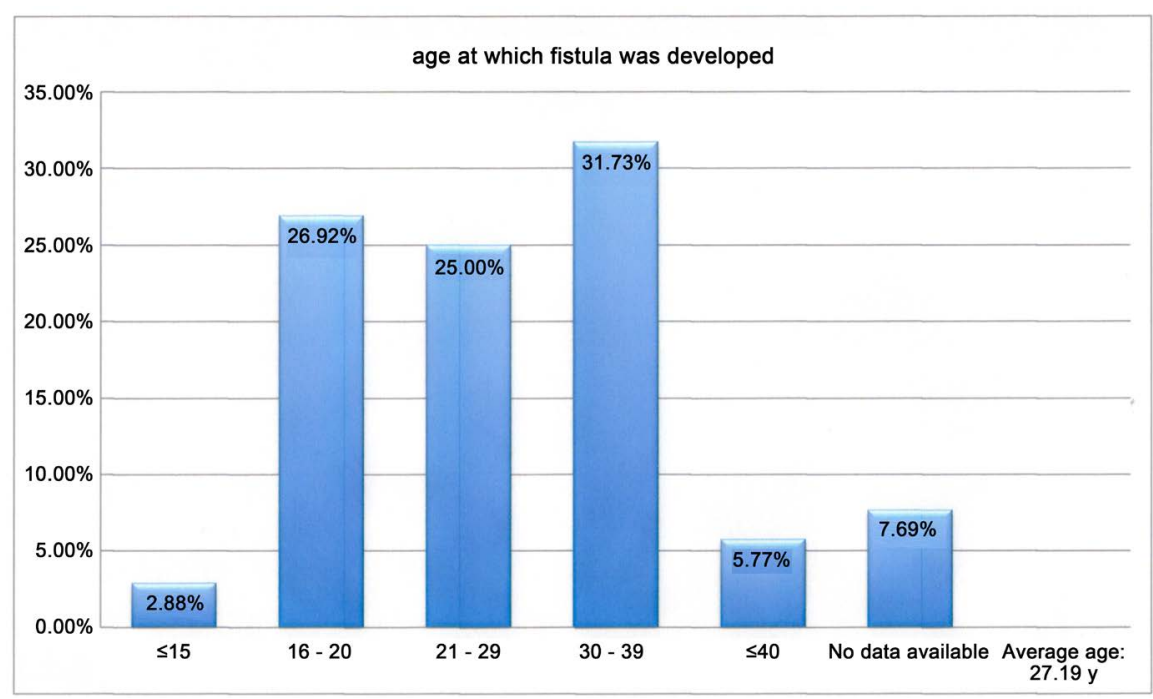

Figure 3. Age at which OF developed.

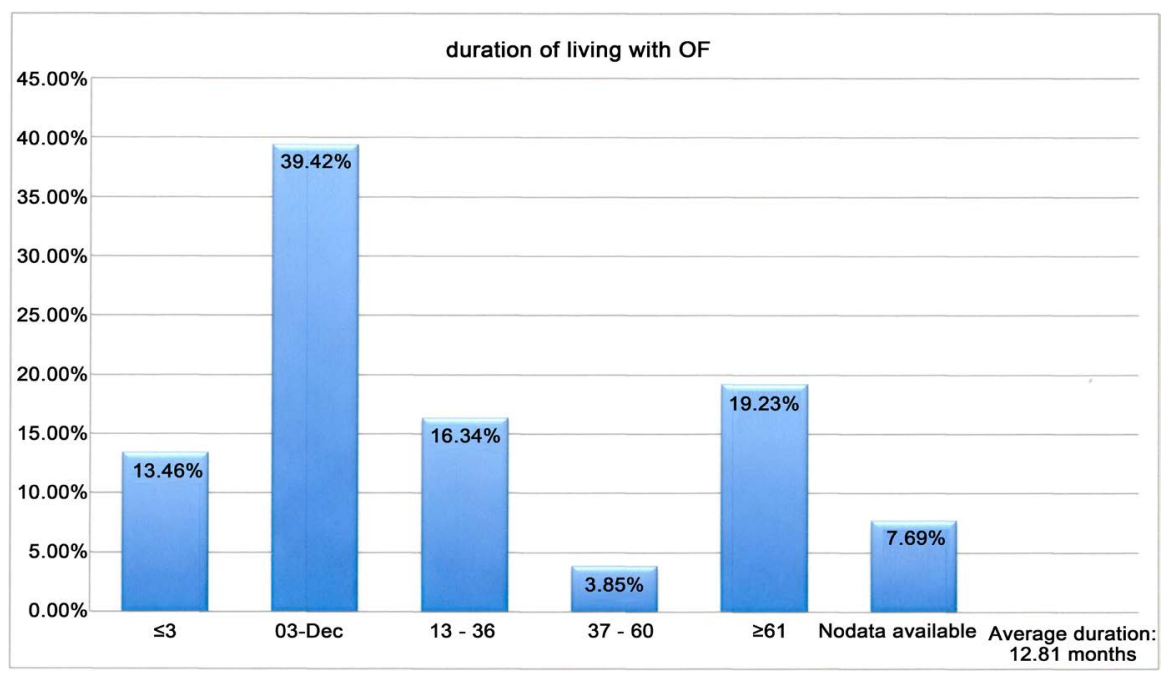

Figure 4. Duration of living with OF.

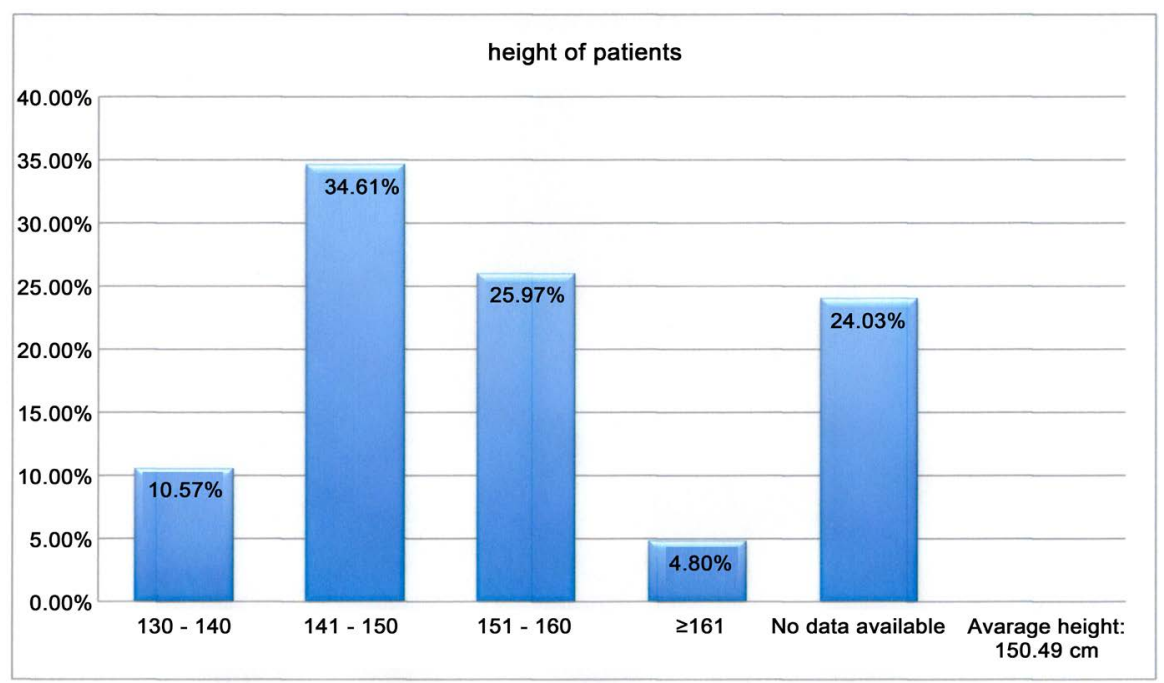

Figure 5. Height of patients. 


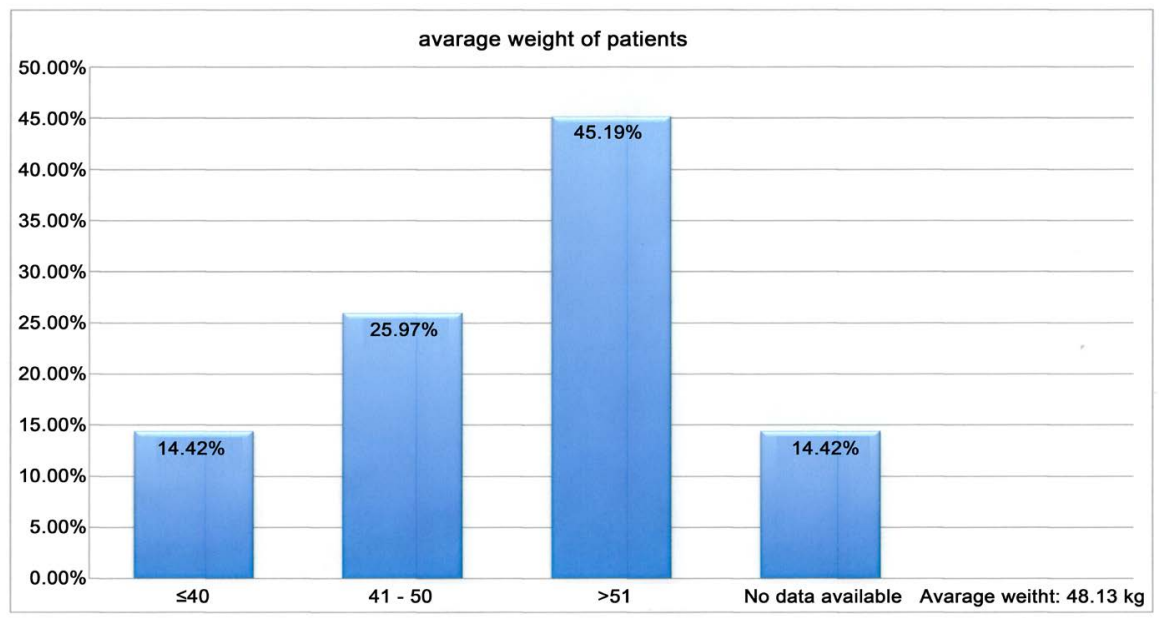

Figure 6. Weight of patients.

Table 2. Delivery characteristics.

\begin{tabular}{|c|c|c|c|}
\hline Parity at occurrence of fistula-Figure 7 & \multicolumn{2}{|c|}{ Number of patients. (\%) } & \multirow[t]{2}{*}{$104=100 \%$} \\
\hline 1 & 33 & $31.73 \%$ & \\
\hline 2 & 14 & $13.46 \%$ & \\
\hline 3 & 12 & $11.53 \%$ & \\
\hline 4 & 12 & $11.53 \%$ & \\
\hline 5 & 11 & $10.57 \%$ & \\
\hline 6 & 10 & $9.61 \%$ & \\
\hline$\geq 6$ & 9 & $8.65 \%$ & \\
\hline No data available & 3 & $2.88 \%$ & \\
\hline Duration of labour-Figure 8 & \multicolumn{2}{|c|}{ Number of patients. (\%) } & $104=100 \%$ \\
\hline$\leq 12 \mathrm{~h}$ & 17 & $16.34 \%$ & \\
\hline $13-24 \mathrm{~h}$ & 28 & $26.92 \%$ & \\
\hline $25-48 \mathrm{~h}$ & 25 & $24.03 \%$ & \\
\hline$\geq 49 \mathrm{~h}$ & 16 & $15.38 \%$ & \\
\hline No data available & 18 & $17.30 \%$ & \\
\hline \multicolumn{4}{|l|}{ Average duration of labour: $31.3 \mathrm{~h}$} \\
\hline Place of delivery-Figure 9 & \multicolumn{2}{|c|}{ Number of patients. (\%) } & $104=100 \%$ \\
\hline Home & 4 & $3.84 \%$ & \\
\hline Dispensary/health centre & 1 & $0.96 \%$ & \\
\hline Hospital & 96 & $92.30 \%$ & \\
\hline No data available & 3 & $2.88 \%$ & \\
\hline Delivered by & \multicolumn{2}{|c|}{ Number of patients. (\%) } & $104=100 \%$ \\
\hline Relative & 0 & & \\
\hline TBA (Traditional Birth Attendant) $\left({ }^{*} 4\right)$ & 3 & $2.88 \%$ & \\
\hline Midwife & 21 & $20.19 \%$ & \\
\hline Doctor & 73 & $70.19 \%$ & \\
\hline No data available & 7 & $6.73 \%$ & \\
\hline
\end{tabular}




\begin{tabular}{|c|c|c|c|}
\hline Mode of delivery-Figure 10 & \multicolumn{2}{|c|}{ Number of patients. (\%) } & $104=100 \%$ \\
\hline SVD & 28 & $26.92 \%$ & \\
\hline Instrumental delivery & 5 & $4.80 \%$ & \\
\hline Cesarean section $(\mathrm{CS})\left({ }^{\star} 5\right)$ & 69 & $66.34 \%$ & \\
\hline No data available & 2 & $1.92 \%$ & \\
\hline Duration in health facility until Birth $(h)$ & \multicolumn{2}{|c|}{ Number of patients. (\%) } & $104=100 \%$ \\
\hline$\leq 6 \mathrm{~h}$ & 30 & $28.85 \%$ & \\
\hline $6-12 \mathrm{~h}$ & 15 & $14.42 \%$ & \\
\hline $13-24 \mathrm{~h}$ & 17 & $16.35 \%$ & \\
\hline $25-48 \mathrm{~h}$ & 5 & $4.81 \%$ & \\
\hline$\geq 49 \mathrm{~h}$ & 7 & $6.73 \%$ & \\
\hline No data available & 30 & $28.85 \%$ & \\
\hline \multicolumn{4}{|l|}{ Average time in health facility $24.89 \mathrm{~h}$} \\
\hline Delivery outcome—Figure 11 & \multicolumn{2}{|c|}{$105=100 \%-$ once twins } & \\
\hline Live birth & 22 & $21.15 \%$ & \\
\hline Still birth & 74 & $71.15 \%$ & \\
\hline No data available & 9 & $8.57 \%$ & \\
\hline Sex of baby-Figure 12 & \multicolumn{2}{|c|}{$105=100 \%$} & \\
\hline $\mathrm{F}$ & 30 & $28.57 \%$ & \\
\hline M & 60 & $57.14 \%$ & \\
\hline No data available & 15 & $14.29 \%$ & \\
\hline
\end{tabular}

$-31.73 \%$ of the women developed the fistula in during their first delivery; - $92.3 \%$ delivered in a hospital; $66.34 \%$ by Cesarean section; - $71.15 \%$ had stillborn babies; - Twice as many babies were male than female (57.14\% versus $28.84 \%)$; Table Legend: $\left({ }^{*} 4\right) \mathrm{TBA}=$ Traditional Birth Attendant; $\left({ }^{*}\right) \mathrm{CS}=$ Cesarean Section.

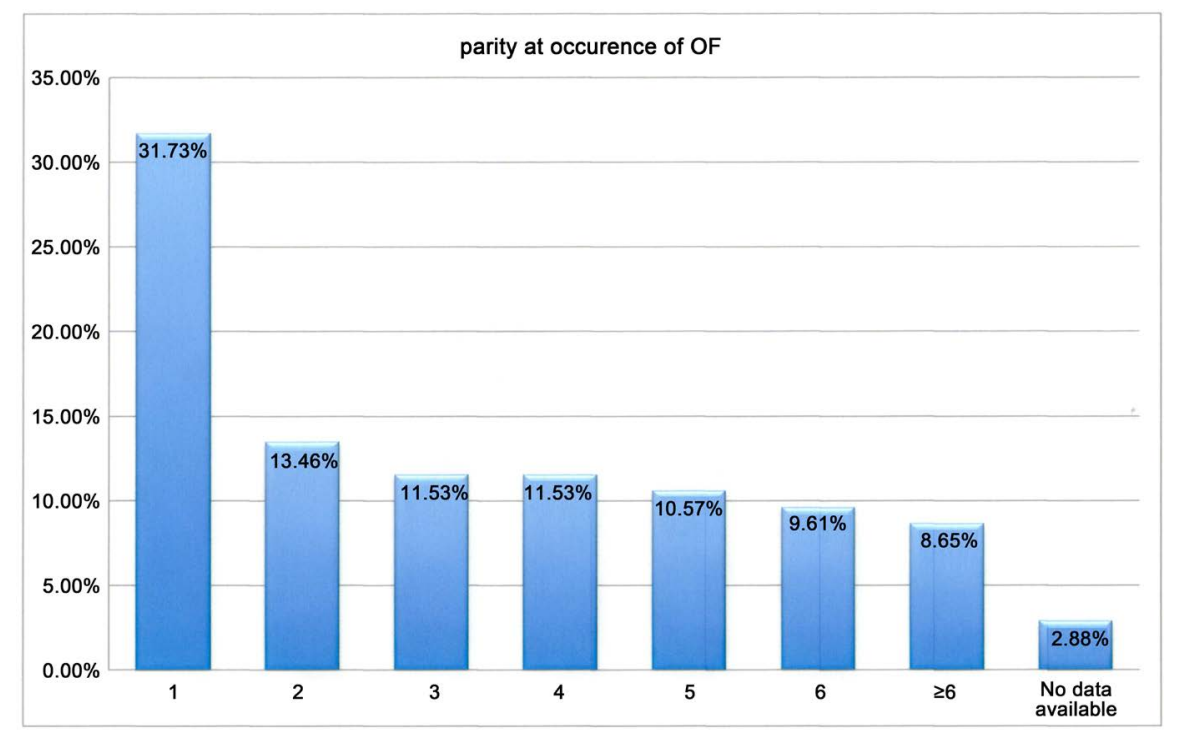

Figure 7. Parity at occurrence of OF. 


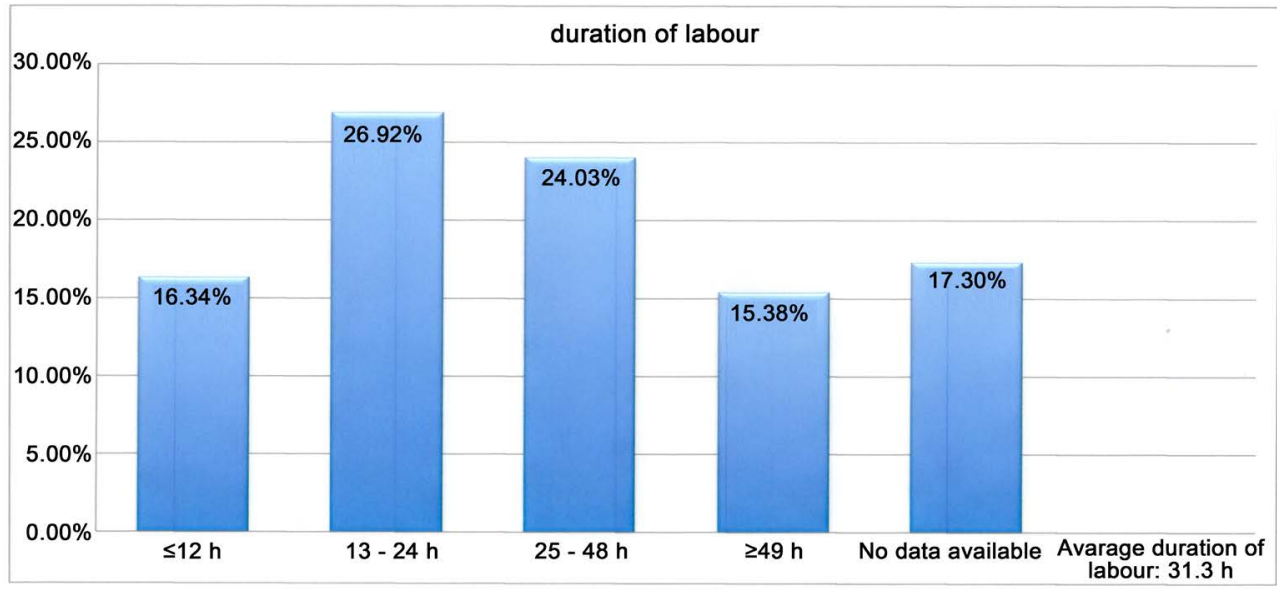

Figure 8. Duration of labour.

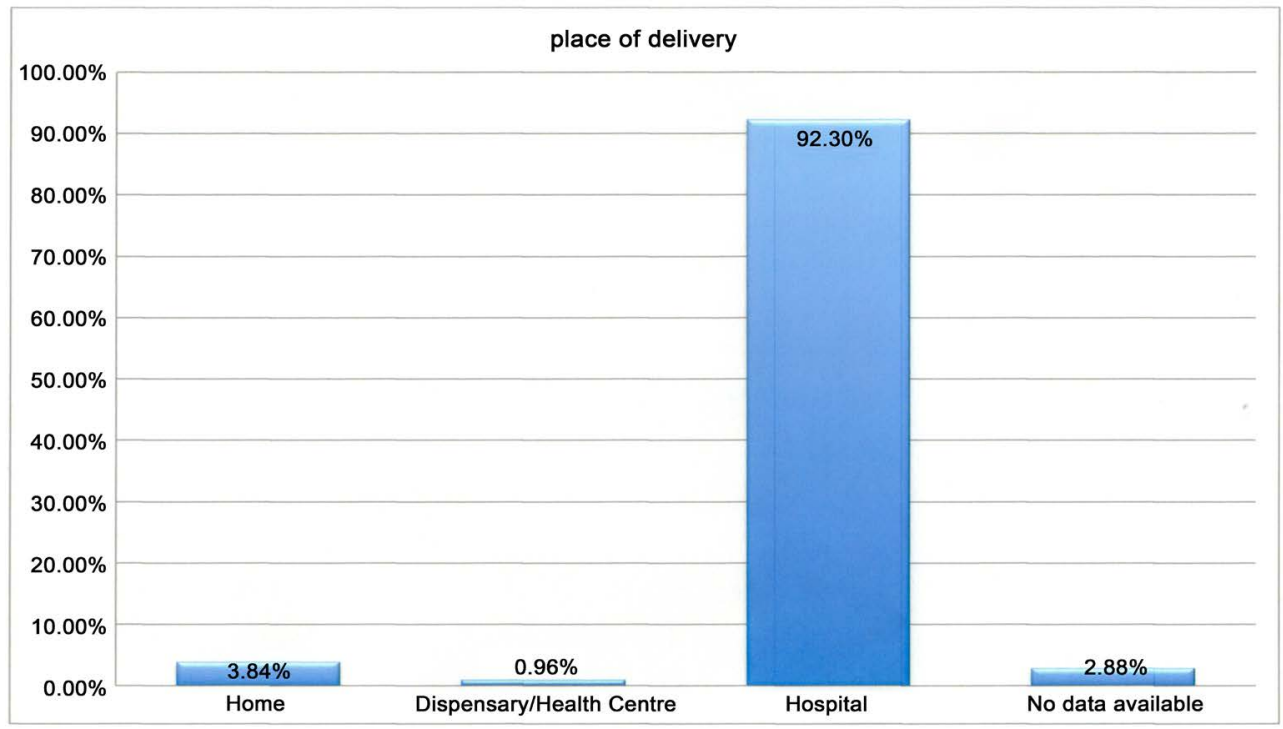

Figure 9. Place of delivery.

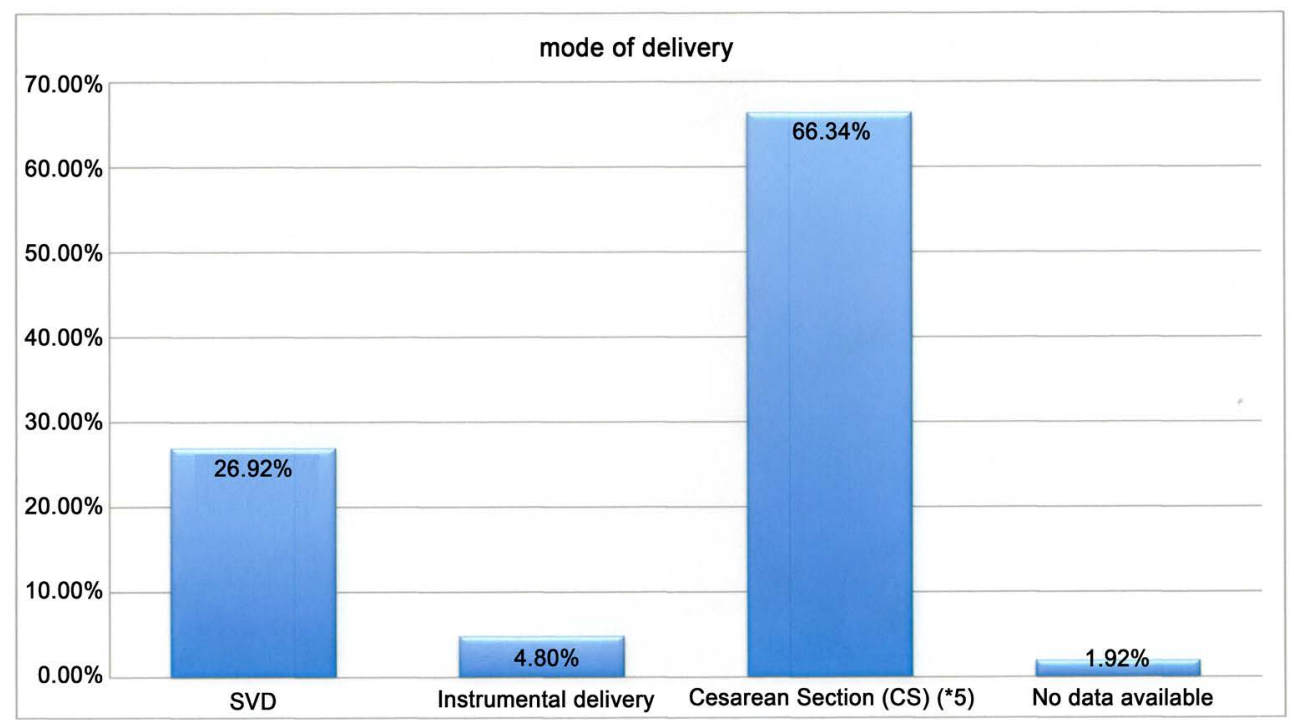

Figure 10. Mode of delivery. 


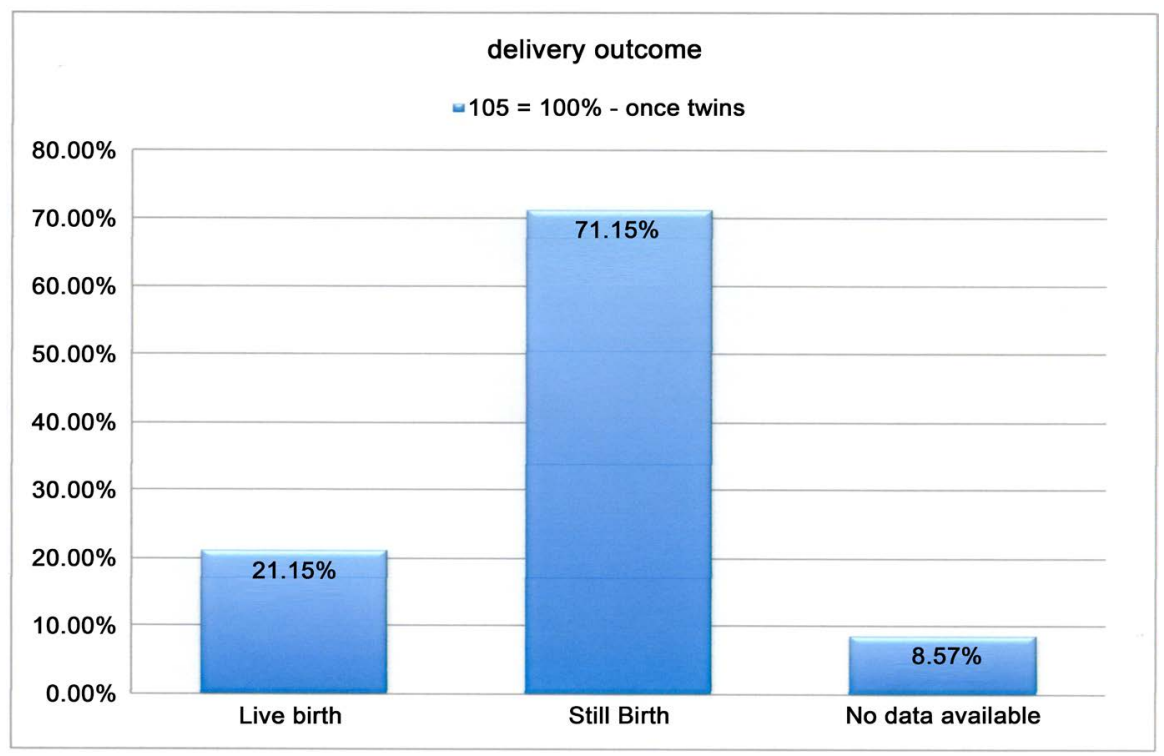

Figure 11. Delivery outcome.

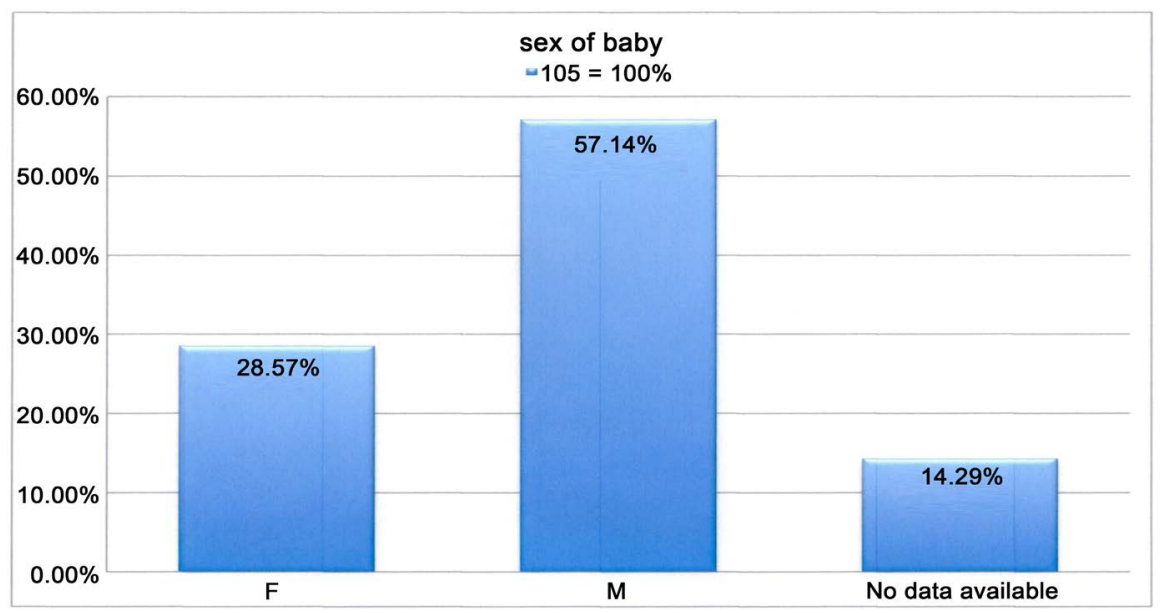

Figure 12. Sex of baby.

Table 3. Clinical characteristics.

\begin{tabular}{|c|c|c|c|}
\hline Number of previous repairs-Figure 13 & \multicolumn{2}{|c|}{ Number of patients. $(\%)$} & $104=100 \%$ \\
\hline 0 & 75 & \multicolumn{2}{|l|}{$72.11 \%$} \\
\hline 1 & 18 & \multicolumn{2}{|l|}{$17.30 \%$} \\
\hline 2 & 5 & \multicolumn{2}{|l|}{$3.32 \%$} \\
\hline 3 & 2 & \multicolumn{2}{|l|}{$1.92 \%$} \\
\hline$>4$ & 2 & \multicolumn{2}{|l|}{$1.92 \%$} \\
\hline No data available & 2 & \multicolumn{2}{|l|}{$1.92 \%$} \\
\hline $\begin{array}{l}\text { VVF ( }{ }^{*} 6 \text { ) classification-Waaldijk }\left({ }^{*}\right) \\
\text { Type of fistulas-Figure } 14 \text { + Figure } 15\end{array}$ & \multicolumn{2}{|c|}{ Number of patients. (\%) } & $104=100 \%$ \\
\hline Typ I: & 54 & $51.92 \%$ & (\% of all $V V F)$ \\
\hline $\operatorname{VCVF}\left({ }^{*} 8\right)$ & 28 & $26.92 \%$ & (\% of all VVF) \\
\hline Typ I & 26 & $25.00 \%$ & \\
\hline
\end{tabular}




\section{Continued}

\begin{tabular}{|c|c|c|c|}
\hline Typ II: & 46 & $44.23 \%$ & $104=100 \%$ \\
\hline $\mathrm{Aa}$ & 20 & $19.23 \%$ & \\
\hline $\mathrm{Ab}$ & 4 & $3.84 \%$ & \\
\hline $\mathrm{Ba}$ & 10 & $9.61 \%$ & \\
\hline $\mathrm{Bb}$ & 12 & $11.53 \%$ & \\
\hline $\operatorname{RVF}\left({ }^{*} 9\right)$ & 0 & & \\
\hline Others & 5 & $4.88 \%$ & \\
\hline Combined fistula (VVF + RVF) & 0 & & \\
\hline$V C V F+C S$-Figure 16 & Nun & ber of patients. (\%) & $104=100 \%$ \\
\hline $\mathrm{VCVF}+\mathrm{CS}$ & 25 & $24.04 \%$ & \\
\hline VCVF without CS & 3 & $2.88 \%$ & \\
\hline$V C V F$ - mode of delivery-Figure 17 & Nun & ber of patients. (\%) & $28=100 \%$ \\
\hline CS & 25 & $89.28 \%$ & \\
\hline INSTRUMENTAL (vacuum) & 1 & $3.57 \%$ & \\
\hline SVD & 1 & $3.57 \%$ & \\
\hline No data available & 1 & $3.57 \%$ & \\
\hline$C S+T_{y p} I($ other than VCVF) & 13 & & \\
\hline$C S+T_{y p} I I$ & 25 & & $25=100 \%$ \\
\hline II Aa & 8 & $32 \%$ & \\
\hline II $\mathrm{Ab}$ & 0 & & \\
\hline II Ba & 8 & $32 \%$ & \\
\hline II Bb & 9 & $36 \%$ & \\
\hline$C S+T_{Y P} I I I$ & 3 & $2.89 \%$ & $104=100 \%$ \\
\hline Conclusion & & & $104=100 \%$ \\
\hline $\begin{array}{l}\text { VVF definitely iatrogenic } \\
\text { (ureteric, VCVF + live baby) }\end{array}$ & \multicolumn{3}{|c|}{$\begin{array}{l}4(\text { ureteric })+25(\mathrm{VCVF}+\mathrm{CS})=>\mathbf{2 9} \\
\mathbf{2 7 . 8 9 \%} \quad \text { (out of } 104)\end{array}$} \\
\hline $\begin{array}{c}\text { VVF probably iatrogenic } \\
\text { (Vault fistula after CS/ Hysterectomy) }\end{array}$ & \multicolumn{3}{|c|}{8 but not included in the study } \\
\hline VVF likely iatrogenic (VCVF + stillbirth (SB)) & \multicolumn{3}{|c|}{$\begin{array}{l}\text { 16-differentiation below. } \\
\text { some VCVF no data if SB or alive }\end{array}$} \\
\hline $\mathrm{VCVF}+\mathrm{SB}$ & 16 & $15.39 \%$ & $104=100 \%$ \\
\hline $\mathrm{VCVF}+\mathrm{CS}+\mathrm{SB}$ & 14 & $13.46 \%$ & $104=100 \%$ \\
\hline \multicolumn{4}{|l|}{ VVF ischemic } \\
\hline VVF iatrogenic $(\mathrm{CS}){ }^{\star} \underline{1}$ & \multicolumn{2}{|c|}{$29+8=37 \quad 35.58 \%$} & $104=100 \%$ \\
\hline VVF iatrogenic vacuum & 2 & $1.92 \%$ & \\
\hline Ureteric & 5 & $4.88 \%$ & \\
\hline VVF + Stress incontinence & 3 & $2.88 \%$ & \\
\hline $\mathrm{VVF}+\mathrm{RVF}$ & 0 & & \\
\hline Perineal tear & 0 & & \\
\hline No data & 2 & & \\
\hline
\end{tabular}

- $72.11 \%$ were operated for the first time; - 51.92\% had Type I fistula, out of them $26.92 \%$ (=28 women) VCFV's; - 53 were of iatrogenic origin (all from definitely to likely); ${ }^{\star} 1$ according to the definition by Raassen-see above. Table Legend: $\left({ }^{*} 6\right)$ VVF $=$ Vesico Vaginal Fistula; $\left({ }^{*} 7\right)$ Classification by Kees Waaldijk-see also above under Main Objective; $\left({ }^{*} 8\right)$ VCVF $=$ vesico cervical; $\left({ }^{*} 9\right)$ RVF $=$ Recto Vaginal Fistula. 


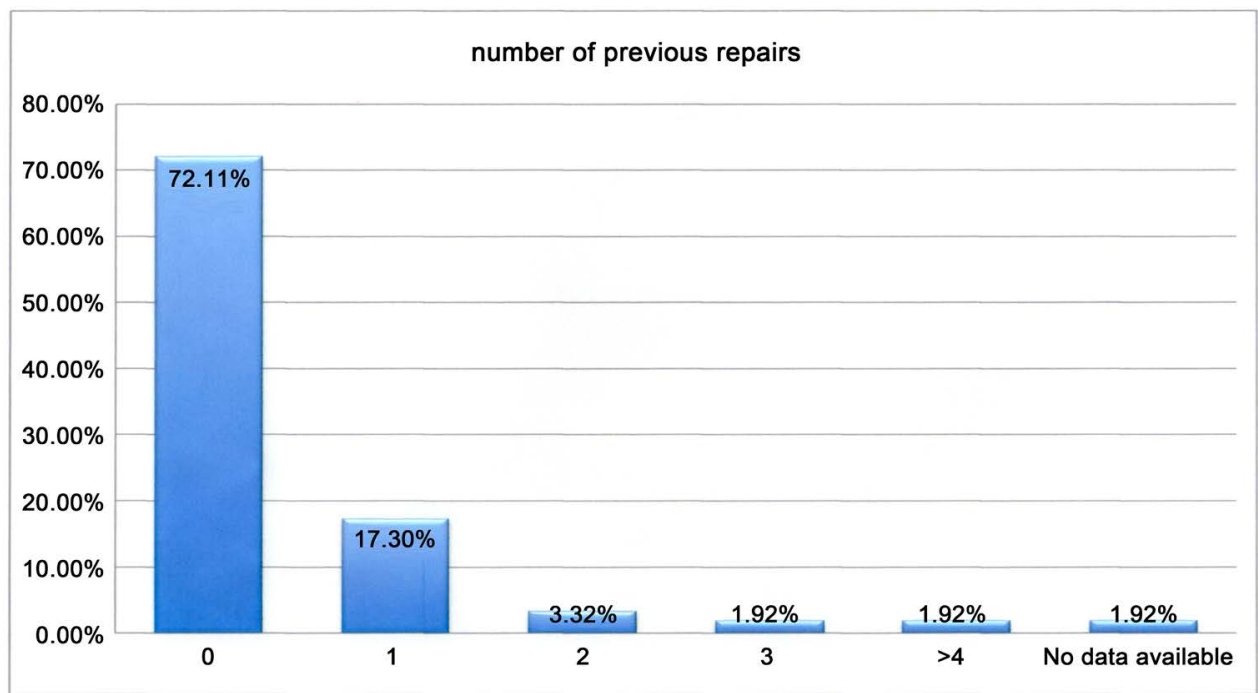

Figure 13. Numbers of previous repairs.

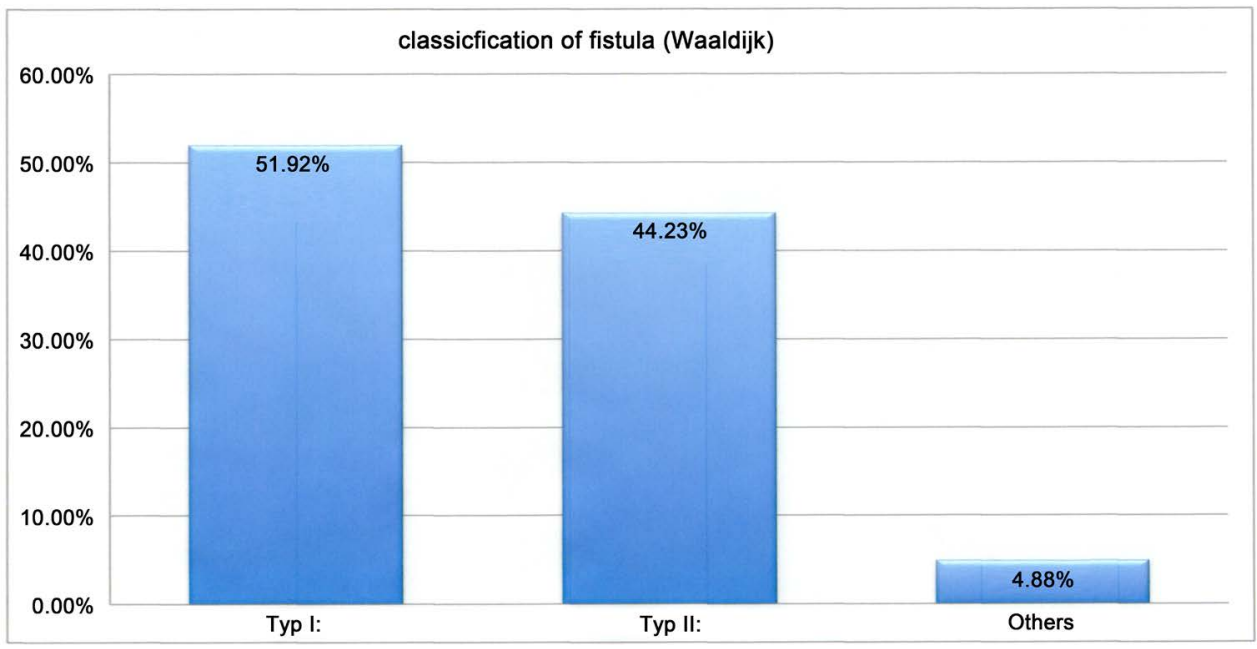

Figure 14. Classification of Waaldijk.

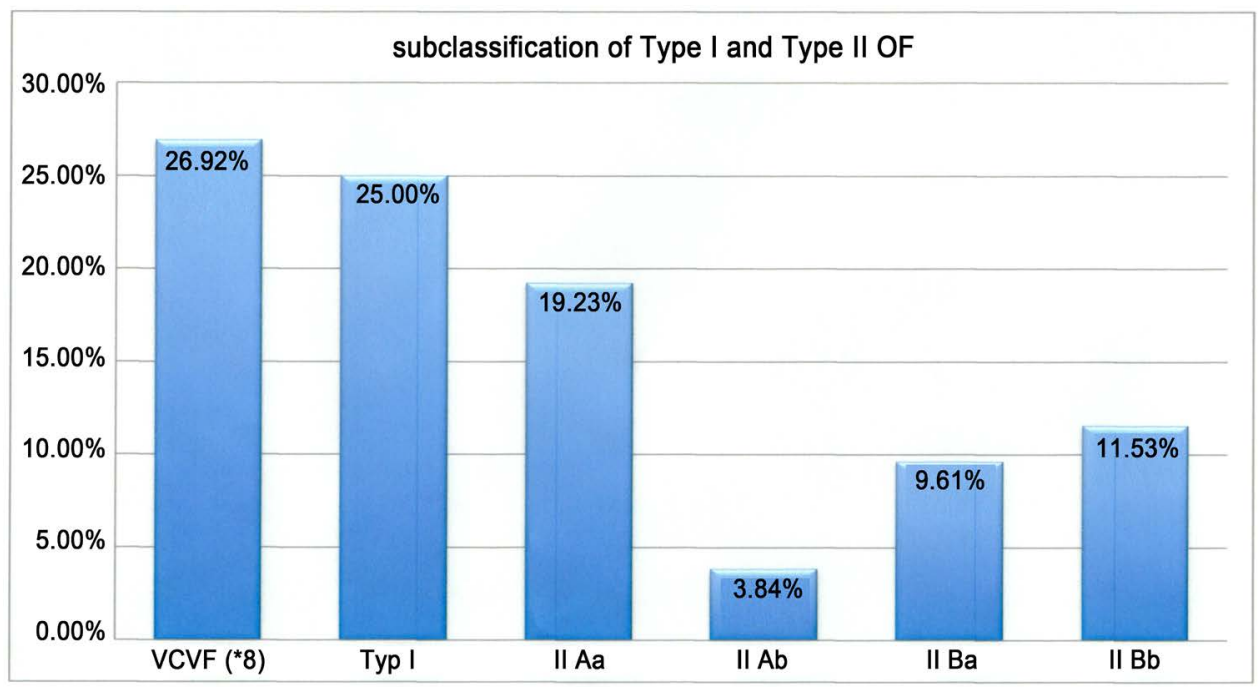

Figure 15. Sub classification typ I + II. 


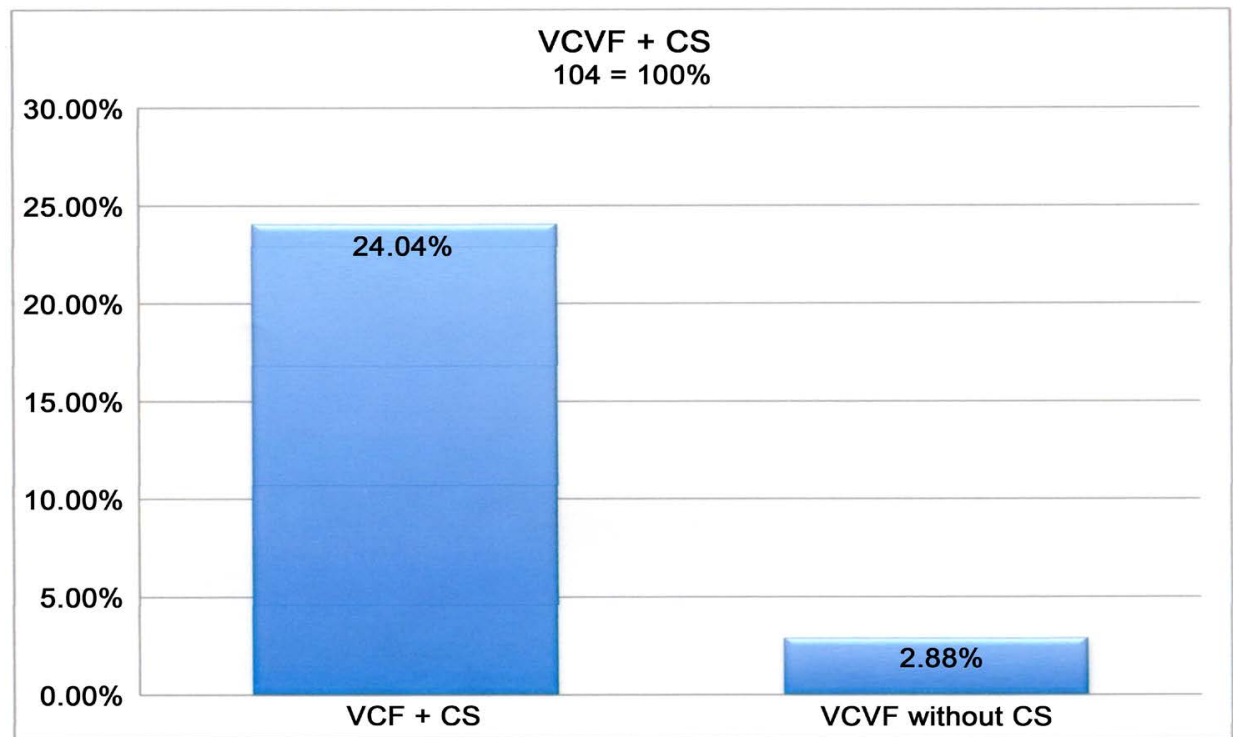

Figure 16. VCVF + CS .

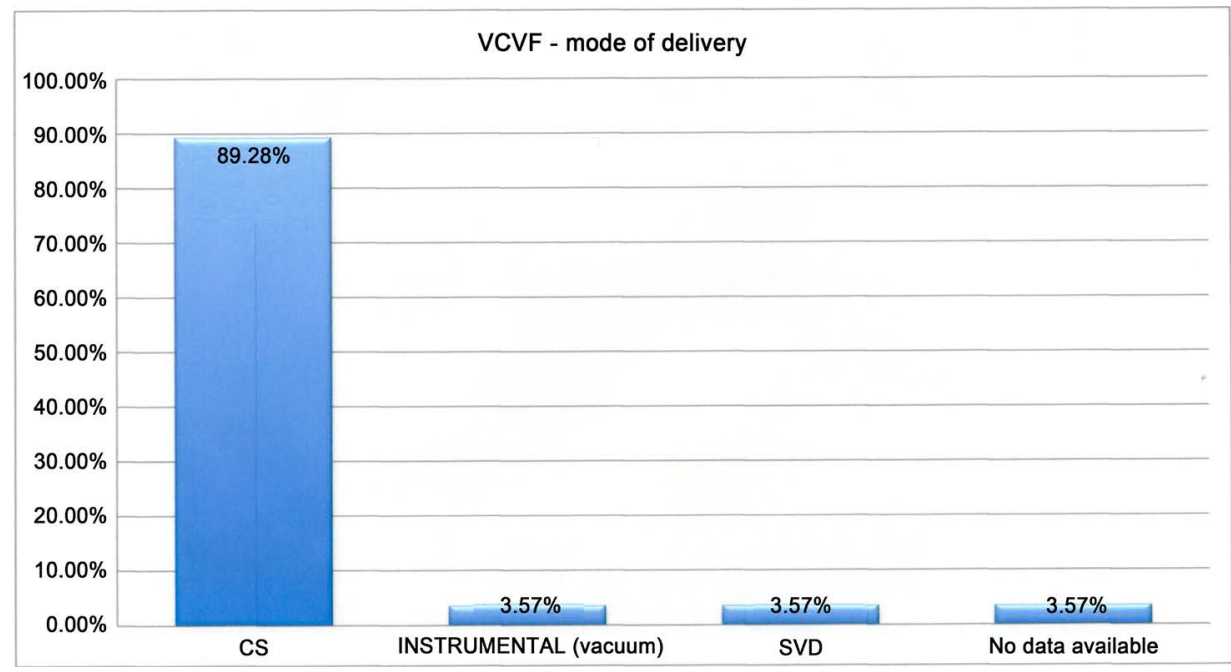

Figure 17. VCVF-mode of delivery.

\section{$[27]^{*}$ Classification of Kees Waaldijk is as follows:}

The classification by Kees Waaldijk is a "classification of fistulas according to anatomic/physiologic location". It is "based on the quantitative and qualitative amount of tissue loss of the continence/closing mechanism" and it is "presented according to the anatomic/physiologic location with consequences for operation technique and prognosis:

- Type I fistulas not involving the continence/closing mechanism,

- Type II fistulas involving the continence/closing mechanism,

- And type III miscellaneous".

\section{See Figure 18}

"The transition from type I into type II fistulas is at $4-5 \mathrm{~cm}$ whilst the transition from type IIA into type IIB fistulas is at $1-1.5 \mathrm{~cm}$ from the external urethra opening." 


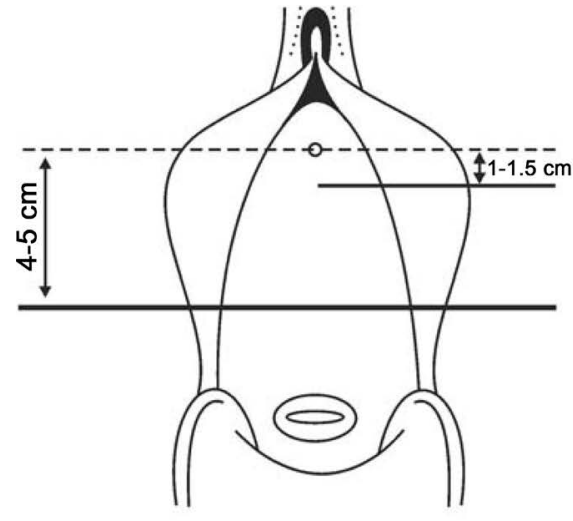

continence/closing mechanism: fronta

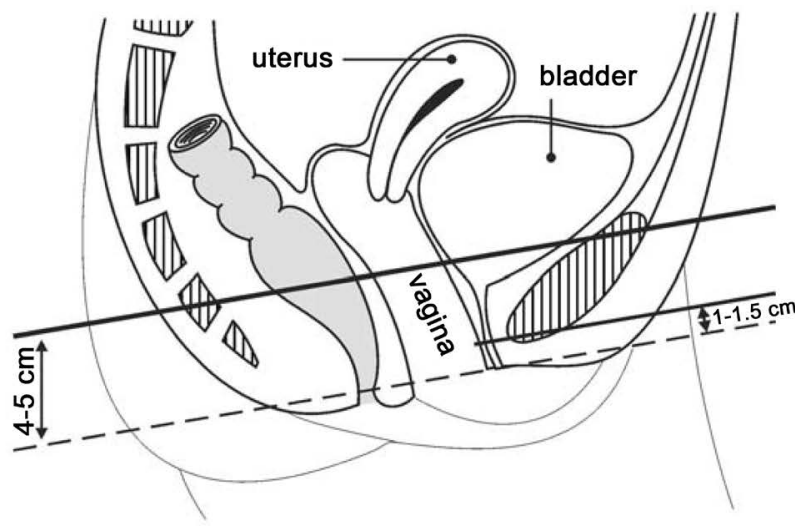

continence/closing mechanism: sagittal

kees

Figure 18. Continence closing mechanism frontal and lateral @ Kees Waaldijk.

Table 4. Classification of fistulas according to size @ Kees Waaldijk.

\begin{tabular}{cc}
\hline Small & $<2 \mathrm{~cm}$ \\
Medium & $2-3 \mathrm{~cm}$ \\
Large & $4-5 \mathrm{~cm}$ \\
Extensive & $>6 \mathrm{~cm}$ \\
\hline
\end{tabular}

"Classification of fistulas according to anatomic/physiologic location.

I fistulas not involving the continence/closing mechanism.

II fistulas involving the continence/closing mechanism.

A without (sub)-total urethra involvement.

a without circumferential defect.

b with circumferential defect.

B with (sub)-total urethra involvement.

a without circumferential defect.

b with circumferential defect.

III miscellaneous, e.g. ureter fistulas and other exceptional fistulas.

An additional classification is presented according to the fistula size: small, medium, large and extensive", see Table 4.

"The operation in order to close the fistula and to restore continence becomes progressively more complicated from type I thru type IIBb whilst the prognosis as to closure and continence worsens progressively; the same applies from small thru extensive.

\section{Surgical objectives:}

- Close the fistula,

- Make the patient continent,

- Operation: meticulous water-tight closure of bladder.

Type I: only closure.

Type IIAa: closure and something has to be done about continence.

Type IIAb: circumferential repair by end-to-end vesico urethrostomy.

Type IIBa: (repair) + urethra reconstruction with functional urethra tissue. 
Table 5. Treatment outcome.

\begin{tabular}{|c|c|c|c|}
\hline Type of Fistula & \multicolumn{3}{|c|}{ Number of Patients (\%) } \\
\hline VVF total & \multicolumn{3}{|c|}{$104=100.00 \%$} \\
\hline Dry & 88 & \multicolumn{2}{|l|}{$84.61 \%$} \\
\hline Leaking & 16 & \multicolumn{2}{|l|}{$15.38 \%$} \\
\hline $\begin{array}{l}\text { Dye test negative but leaking } \\
\text { (VVF closed but ureteric fistula remains) }\end{array}$ & 3 & \multicolumn{2}{|c|}{$2.88 \%$ out of 104} \\
\hline $\begin{array}{l}\text { Dye test negative but leaking } \\
\text { (VVF closed but Stress incontinence remains) }\end{array}$ & 2 & \multicolumn{2}{|c|}{$1.92 \%$ out of 104} \\
\hline$V V F+(C S)\left({ }^{*} 11\right)$ & 53 & \multirow[t]{2}{*}{$50.96 \%$} & $104=100 \%$ \\
\hline Dry & 42 & & \\
\hline Leaking & 11 & \multirow{4}{*}{\multicolumn{2}{|c|}{$10.58 \%$ see further explanation below }} \\
\hline Ureteric & 4 & & \\
\hline Dry & 4 & & \\
\hline Leaking & 0 & & \\
\hline EUO-BW $\left({ }^{*} 12\right)$ parameter obtained from & \multicolumn{3}{|c|}{95 patients $(91.34 \%)$} \\
\hline Average & \multicolumn{3}{|c|}{$10.65 \mathrm{~cm}$} \\
\hline EUO-BC $\left({ }^{*} 13\right)$ parameter obtained from & \multicolumn{3}{|c|}{94 patients $(90.38 \%)$} \\
\hline Average & \multicolumn{3}{|c|}{$2.43 \mathrm{~cm}$} \\
\hline No data available from & \multicolumn{3}{|c|}{9 patients $(8.65 \%)$} \\
\hline
\end{tabular}

Table Legend: $\left({ }^{*} 10\right)$ VVF $=$ Vesico Vaginal Fistula; $\left({ }^{*} 11\right)$ CS $=$ Cesarean Section; $\left({ }^{*} 12\right)$ EUO = External Urethra Opening; (EUO - BW $=$ distance between external urethra opening and Bladder Wall); $\left.{ }^{\star}{ }^{\star} 12\right) \mathrm{BW}=$ Bladder Wall; $\left({ }^{*} 13\right) \mathrm{BC}=$ Bladder Catheter.

Type IIBb: (circumferential repair) + urethra reconstruction with other tissue (scar tissue, paraurethra tissue, bulbocavernosus muscle or bladder); often in two stages.

Type III: ureter reimplantation or something else".

Postoperative:

Indwelling bladder catheter-FOLEY catheter Ch 18-(is inserted) for minimum period of 2 weeks postoperatively.

\section{* 1 definition by Raassen-(Emphasis added)}

"iatrogenic fistulas can be considered to cover a spectrum, ranging from "definitely iatrogenic" to "likely iatrogenic".

- Three groups of fistulas are definitely iatrogenic. All ureteric injuries are iatrogenic, whether following CS, CS/hysterectomy, or planned gynecological hysterectomy. Vesico-vaginal vault fistulas appearing after hysterectomy for gynecological reasons, such as fibroids, are iatrogenic.

Finally, the delivery of a live baby by CS is rarely associated with pressure necrosis.

If the baby is living, VCVF located between the lower segment of the uterus/cervix and the bladder strongly suggests an accidental bladder injury (suture 
or cut) during a CS.

- Vault fistulas following emergency hysterectomy for a ruptured uterus or CS/hysterectomy are probably iatrogenic...

- Vesico-(utero)/-cervico-vaginal fistulas following CS for a stillborn baby are likely to be iatrogenic.

In cases where the baby was lost, this analysis included VCVFs less than $3 \mathrm{~cm}$ and located clearly in the cervical canal, based on author experience.

A patient history of previous CS or live birth increases the likelihood that the injury is iatrogenic.

\subsection{Outcome}

88 women (84.61\%) were discharged home being dry, 16 (15.38\%) were still leaking, 2 of them had their fistula closed but still suffered from remaining stress incontinence and will need further surgery; 4 have lost the urethra or most of it and have limited perspective to become continent, due to the severity of their injury. One patient had big bladder stones and needs to come back in 6 months for the definitive repair, one has severe vaginal stenosis, both ureters visible and needs either a different approach or a ureteric diversion, 4 have ureter fistulas and with the remaining the 3 the repair was not successful.

In comparison: Loposso's overall closure rate after the first surgical treatment was $65 \%$. The continence rate of the patients with a successful closure was $63 \%$ [28].

Of those women who can certainly be classified as ischemic fistulas 28 went home dry; the other 4 were still leaking.

(Differentiation:

- 2 patients had still has a type IIBb fistula, after having had 4/5, resp. 3 times surgery before.

- 4 patients have remaining ureteric fistulas, after the first VVF was closed.

- 1 patient had fistula type IIAb, had 1 previous surgery.

- 1 patient had fistula type I, had no previous surgery.

- 1 patient had 2 fistulas. one type I, the second type IIBb, type IIAb, had no previous surgery.

- 1 patient had fistula type IIAb, had 3 previous surgeries.

- 1 patient has multiple fistulas and no urethra, had this time bladder stones removed, had no previous surgery.

- 1 patient had fistula type I, had no previous surgery, and now her dye test was negative but she still has stress incontinence that needs further treatment.

- 1 patient had fistula type IIBb, had no previous surgery, and has no functioning urethra and very stenotic vagina.

- 1 patient had fistula type IIBb, had no previous surgery, and now her dye test was negative but she still has stress incontinence that needs further treatment).

$30(96.77 \%)$ out of 31 women with definitely iatrogenic VVF were dry when discharged; only 1 woman with an iatrogenic fistula was still leaking-she had a negative dye test, so she also has a remaining ureter fistula, that needs to be 
closed in the next surgery.

As we tried to differentiate between ischemic and iatrogenic fistula these results clearly point out that iatrogenic fistulas, such as VCVF'S or ureter fistulas that needed abdominal approach have a higher probability to be successful closed.

The patients will be followed up after 6 months by the outreach team from CCBRT Dar es Salaam.

\section{Discussion}

The mean age of the 104 women who were included in the study was, 28.48 years (15 to 66 ) old, their mean age when they developed the fistula was 27.19 years (15 to 54 ). The time they had been living with the fistula was on average 12.8 months ( 1 month to 45 years!) As Sub-Saharan Africa is the region in the world with the highest level of adolescent childbearing it is not surprising that near 1/5 (18.26\%) of our patients were teenagers. An older source also found that 42 to $54 \%$ of the fistula patients were less than 20 years old [3] [20].

Two thirds of the women reported that they were married (63.46\%). Out of the 61 women $(58.65 \% ; 61=100 \%)$ who had primary education $35(=57.38 \%$ of 61), (33.65\% of all 104) had finished STD 7. $29.80 \%$ (31 of our 104 study patients) had no education at all; this is little compared to studies that found the illiteracy level of women being often between $78 \%$ and $95 \%$ [3].

87.5\% tested HIV negative and $5.77 \%$ were HIV positive. The result represents approximately the distribution of HIV prevalence of $5.4 \%$ in the overall population of Tanzania but is less than the result for women of whom the prevalence in the 2012 survey was $6.2 \%$ to $7.5 \%$ [30] [31].

The physical characteristics of the women also confirmed what other investigators have found: Tebeu found that "many of the fistula patients were shorter than $150 \mathrm{~cm}$ tall $(40 \%-79.4 \%)$ " [3]. In our study $45.18 \%$ of the women were 150 $\mathrm{cm}$ or smaller and another $25.97 \%$ between 151 and $160 \mathrm{~cm}$.

Their weight was accordingly often low, we found a median of $48.12 \mathrm{~kg}$ (35$96 \mathrm{~kg}$ ).

Holme et al. from Zambia described a median weight of $46 \mathrm{~kg}(25-92 \mathrm{~kg})$ among their patients [31].

In $31.73 \%$ of the women the fistula occurred with their first delivery, but $18.26 \%$ experienced the problem after they already had given birth 6 or more times. Tebeu found collectives where between $31.4 \%$ and $66.7 \%$ were primiparous at the moment of occurrence [5]. Wall and Arrowsmith et al. refer to older studies and found data from various countries that the percentages of primiparous women were between $31 \%$ and $81 \%$ [20].

$11.54 \%$ of the women in our study reported of having been in labour for 25 or even more hours ( 1 to $121 \mathrm{~h}$ !) with an average of 31.3 hours which indicates that these women got into obstructed labour before developing a fistula. Other investigators confirm these findings. Tebeu mentions the duration of labour among the 7 risk factors he identified for developing an obstetric fistula. In his study the mean duration of labour among the fistula patients ranged from 2.5 to 4 days (60 
to $92 \mathrm{~h}$ ) [5]. In the DRC Loposso found in a collective of 146 women of whom 63.4\% were delivered by CS that the mean duration of labour was $30.7 \mathrm{~h}$ [28].

96 women $(92.30 \%)$ of the 104 women treated at CCBRT for fistula in the investigated time period were delivered in a hospital either by a midwife $(20.19 \%)$ or a doctor $(70.19 \%)$.

Of the 73 women $(70.19 \%)$ delivered by a doctor, 69 of them had a Cesarean Section (94.52\%), yet these women developed fistula. (Out of the 4 remaining 2 were delivered by vacuum, one gave birth by herself and in one case the mode of delivery is not known).

Loposso et al. who published their study "Obstetric fistula in a district hospital in DR Congo: Fistula still occur despite access to caesarean section" in 2014 found a rate of $63.4 \%$ of Cesarean Section as the mode of delivery among the women treated for obstetric fistula [28]. Hilton et al. cite data from Tanzania where now $85 \%$ of women with fistula have delivered by Cesarean Section) [23]. This of course raises more questions: is the most frequent reason still the obstructed labour, is the obstruction mostly at the level of lack of transportation, and is the obstruction on the level of available personnel and material at the health facility level or mostly at the level of knowledge and skill of the health care providers?

The time that went by in the facility where the women finally gave birth was 6 $\mathrm{h}$ or less for nearly one third of them $(28.70 \%)$ another third spent 7 to $24 \mathrm{~h}$ until birth. (31.48\%). 12, (11.11\%) had to wait up to a maximum of $72 \mathrm{~h}$ until their children were born. The remaining 31 women $(28.70 \%)$ could not say how much time went by until the delivery that caused the fistula took place. These time periods remembered by the women might not be accurate enough but will definitely give a time frame that points to the issue of which resources (personnel and material; e.g.: consumables) are available in health centres and hospitals where women give birth.

The outcome of those deliveries is not surprising: $70.47 \%$ of the delivered children were stillborn and twice as many of them were boys; $57.14 \%$ were male and $28.84 \%$ female. Studies from Zambia, Nigeria, Ethiopia and Niger showed stillbirth rates between $78 \%$ and $96 \%$ [5].

Most of the women (72.11\%) who come to CCBRT for fistula repair from all over the country did not have previous surgery to close their fistula. This is accordance with the fact that $52.88 \%$ of the women had developed the fistula not longer than a year before they were asking for treatment in this facility.

Distribution of type of fistula we found is as follows:

- 54 women (51.92\%) had Type I fistulas, of them 28 (26.92\% of the 104 patients) were VCVF's and the remaining 26 (25\% of 104) had other Type I fistulas.

- 46 (44.23\%) were Type II fistulas, out of them type IIAa: $20-(19.23 \%$ of 104); type IIAb: $4-(3.84 \%$ of 104$)$; type IIBa: $10-(9.61 \%$ of 104$)$ and type IIBb: $12-(11.53 \%$ of 104$)$ fistulas.

- 5 (4.88\% of 104$)$ were Type III (= other kind of) fistulas, such as ureteric or 
multiple fistulas.

Two thirds (66.34\%) of women (69 out of 104), presenting with VVF had had CS. Out of these 69, 25 (24.04\%) women had a VCVF, 4 had ureteric fistula that we define in accordance with Raassen's definition as "definitely iatrogenic".

Of the 69 (100\%) women who were delivered of their babies by CS,

$13(25 \%)$ had a VVF type I, 25 (\%) had a VCVF, altogether 38 (55.07\%) to be summarized under type I fistulas, 8 (11.6\%) women had a VVF type IIAa, none had a type IIAb, 8 (11.6\%) had a VVF type IIBa, 9 (13.04\%) had a VVF type IIBb and $3(4.35 \%)$ had VVF type III, this includes ureteric fistulas.

Loposso [28] et al. who also used the Waaldijk classification found among 146 patients with VVF, $56 \%$ type I, and $21 \%$ type III fistulas. The majority of them had undergone a caesarean section (63.4\%) [29].

Paul Hilton already points out an interesting development of occurrence of iatrogenic fistula: as there are less numbers of hysterectomies performed one can observe more iatrogenic injuries in high and middle income countries, possibly due to less trained surgeons and as there are more CS performed in the low income countries more iatrogenic fistulas can be observed as well [23].

\section{Conclusions}

Between $1^{\text {st }}$ January and $31^{\text {st }}$ March 2016, 155 women underwent fistula surgery at CCBRT. 104 of them for VVF, 4 for VVF after TAH, 4 for vault fistulas (of which we could not define better after CS or TAH and therefore were excluded), 25 for SI, 7 for perineal tears, 6 for RVF and 5 for other reasons, such as urethral strictures and bladder stones. $69(66.34 \%)$ of the 104 patients with VVF had been delivered by CS.

Out of these, 12 had CS with live babies and 6 with VCVF at the same time.

The other 6 with CS and live babies had: 1 had a ureteric fistula, 3 had type $\mathrm{IIBb}$ fistulas and 2 had type I fistulas.

25 ( 25 out of $69=36.23 \%$ ) of women with CS definitely had iatrogenic fistula.

As the patients who had VVF type IIBb (using the classification of Kees Waaldijk) that by definition is a more severe injury and has less good prognosis for becoming continent, we found that $12(11.53 \%)$ women had this type of fistula. 6 of them were discharged home being dry, 6 were still leaking urine, one of them having a negative dye test but is still leaking urine although the fistula was closed, due to residual stress incontinence that will need further surgery.

Among the overall results of the women who have undergone VVF surgery 88 (84.61\%) women went home being dry, 16 (15.38\%) were still leaking urine.

Of all our patients one third of the patients suffered from an iatrogenic fistula and $11.5 \%$ had a fistula of type IIBb.

Whereas the VCVFs are sometimes difficult to reach by vaginal surgical approach or end up showing a ureteric fistula as well, the type IIBb fistulas have a less favourable prognosis as to what continence is concerned due to the involvement of the continence mechanism.

In the cohort examined by Raassen et al., they found out of 5959 women op- 
erated between 1994 and 2012 in 11 different countries that 805 equalling 13.2\% had an iatrogenic fistula [25].

As we found a rate of $29.81 \%$ (out of 104 patients) with definitely iatrogenic fistula we do assume that there is a shift in aetiology of VVF.

But as the study populations from Raassen and CCBRT were not in the same time range and not from the same country we recommend that our findings need be compared to data from Tanzania from the past.

In order to get more precise data on whether a fistula is truly iatrogenic Hilton [23] suggested to describe those fistulas as a "true obstetric or ischaemic fistula" where women who experienced obstructed labour, maybe sometimes for days, ultimately delivered a stillborn baby vaginally. He agrees with Raassen [25] as well as referrers to Onsrud [32] and Loposso [28] who describe that women who are delivered by CS of a live baby in a health facility after obstructed labour had been identified and who still develop a VVF "would be reasonably described as having an iatrogenic injury".

The question arises for those women who are transferred to a health facility after delay and are delivered of a stillborn baby and who also end up having a VVF or those who's VVF is an urethrovaginal fistula, a "midvaginal" fistula or an ureterovaginal fistula. Should they be defined as ischemic, as iatrogenic or as a combination of both?

In order to define this better it would be helpful if the history the women can give were more reliable, but this is not very probable as the majority of them still have very little education and how can one possibly expect from a woman in pain to remember all details precisely.

A weakness of this study certainly is that the history taking is often difficult and not exact enough. This applies especially to the duration of labour, the time spent in the hospital (or health facility) before the delivery.

\section{Recommendations}

1) Study a similar group of patients in the near future in the same facility and compare the data in order to see if the patients were delivered by Cesarean Section.

2) Apply the definition of Raassen for a definitely, probably and likely iatrogenic fistula when collecting the data for another study.

3) In order to better prevent women from suffering from this preventable condition the problem, like in other countries needs to be tackled at various levels.

4) Health education as a form of preventive medicine to avoid the occurrence of fistula needs to be reinforced and amplified so that not just the women but also their husbands and partners better understand that and why they should seek help early when the woman give birth.

5) Proper ambulance service will be needed in order to provide obstetric service to the doorstep of every citizen.

6) Enough health facilities all over the country will be essential to avoid 
trouble of traveling long distance in order to attain obstetric care.

7) Adequate consumables need to be constantly available in health facilities.

8) All cadres of service providers, e.g., TBAs, nurse attendants, midwives, clinical assistant, assistant medical officers and medical officers should be offered more training in order to provide adequate service and equally importantly knowing one's own limitations.

9) Working conditions of doctors need to be improved to reduce surgical error this includes: improvement of training of surgical techniques, obstetric decision-making and alternative ways to deliver dead babies. (Are doctors who will be working in the rural areas well enough prepared for the complicated cases of obstructed labour, which they will encounter?

This will provide every region of the country with access to comprehensive obstetric services. Consequently it will reduce the prevalence of VVF and its injury complex.

With our investigation we want to contribute to what former UN SecretaryGeneral Ban Ki-moon is asking for:

"We have a moral obligation, as a global community, to complete the unfinished agenda of eradicating fistula. Together, let us keep our promises to support universal human rights and ensure the health and dignity of women and girls everywhere." [33] (Further reading: [34])

\section{References}

[1] https://www.un.org/en/events/endfistuladay/index.shtml

[2] Adler, A.J., Ronsmans, C., Calvert, C. and Filippi, V. (2013) Estimating the Prevalence of Obstetric Fistula: A Systematic Review and Meta-Analysis. BMC Pregnancy Childbirth, 13, 246. https://doi.org/10.1186/1471-2393-13-246

[3] Hardee, K., Gay, J. and Blanc, A.K. (2012) Maternal Morbidity: Neglected Dimension of Safe Motherhood in the Developing World. Global Public Health, 7, 603 617. https://doi.org/10.1080/17441692.2012.668919

[4] Sjøveian, S., Vangen, S., Mukwege, D. and Onsrud, M. (2011) Surgical Outcome of Obstetric Fistula: A Retrospective Analysis of 595 Patients. Acta Obstetricia et Gynecologica Scandinavica, 90, 753-760. https://doi.org/10.1111/j.1600-0412.2011.01162.x

[5] Tebeu, P.M., Fomulu, J.N., Khaddaj, S., de Bernis, L., Delvaux, T. and Rochat, C.H. (2012) Risk Factors for Obstetric Fistula: A Clinical Review. International Urogynecology Journal, 23, 387-394. https://doi.org/10.1007/s00192-011-1622-x

[6] Rochat, C.H. (2015) Obstetric Fistula. The Geneva Foundation for Medical Education and Research. http://www.gfmer.ch/fistula/Obstetric-fistula-2015.htm

[7] http://www.who.int/life-course/news/events/intl-day-to-end-fistula/en/

[8] World Health Organisation (2008) Managing Obstructed Labour. PDF, 2nd Edition, Geneva, Switzerland, 17-36.

[9] CCBRT, Annual Report 2014, p. 32 +CCBRT, Annual Report 2015.

[10] WHO Press (2015) Trends in Maternal Mortality: 1990 to 2015 Estimates by WHO, UNICEF, UNFPA, World Bank Group and the United Nations Population Division Executive Summary, WHO/RHR/15.23, WHO Press, World Health Organization, 20 Avenue Appia, 1211 Geneva 27, Switzerland. 
[11] American Academy of Family Physicians (AAFP) (2009) GLOBAL ALSO, Global Advanced Support in Obstetrics (2009) 1st Edition, American Academy of Family Physicians (AAFP), 11400 Tomahawk Creek Parkway, Leawood, KS, USA.

[12] Tunçalp, Ö., Tripathi, V., et al. (2015) Measuring the Incidence and Prevalence of Obstetric Fistula: Approaches, Needs and Recommendations. Bulletin of the World Health Organization, 93, 60-62.

http://www.who.int/bulletin/volumes/93/1/14-141473/en/ https://doi.org/10.2471/BLT.14.141473

[13] Fistula Care Plus/Maternal Health Task Force (2014) Fistula Care Plus: International Research Advisory Group Meeting Report, 8-9 July 2014. Engender Health/Fistula Care Plus, New York.

[14] Maheu-Giroux, M., Filippi, V., Samadoulougou, S., Castro, M.C., Maulet, N., Meda, N. and Kirakoya-Samadoulougou, F. (2015) Prevalence of Symptoms of Vaginal Fistula in 19 Sub-Saharan Africa Countries: A Meta-Analysis of National Household Survey Data. The Lancet Global Health, 3, e271-e278. https://doi.org/10.1016/s2214-109x(14)70348-1

[15] Biadgilign, S., Lakew, Y., Reda, A.A. and Deribe, K. (2013) A Population Based Survey in Ethiopia Using Questionnaire as Proxy to Estimate Obstetric Fistula Prevalence: Results from Demographic and Health Survey. Reproductive Health, 10, 14. https://doi.org/10.1186/1742-4755-10-14

[16] https://en.wikipedia.org/wiki/Obstetric_fistula

[17] Ahmed, S. and Tunçalp, Ö. (2015) Burden of Obstetric Fistula: From Measurement to Action. The Lancet Global Health, 3, e243-e244.

https://doi.org/10.1016/s2214-109x(15)70105-1

[18] http://globalfistulamap.org

[19] Onsrud, M., Sjøveian, S., Luhiriri, R. and Mukwege, D. (2008) Sexual Violence-Related Fistulas in the Democratic Republic of Congo. IJOG, 103, 265-269.

[20] Wall, L.L., Arrowsmith, S.D., Briggs, N.D. and Lassey, A. (2001) Urinary incontinence in the developing world: The obstetric fistula. Proceedings of the 2 nd International Consultation on Urinary Incontinence, Paris, 1-67.

[21] Browning, A., Allsworth, J.E. and Wall, LL. (2010) The Relationship between Female Genital Cutting and Obstetric Fistulae. Obstetrics \& Gynecology, 115, 578583. https://doi.org/10.1097/AOG.0b013e3181d012cd

[22] Wikipedia.org. Prevalence of Female Genital Mutilation by Country \# Tanzania

[23] Hilton, P. (2016) Trends in the Aetiology of Urogenital Fistula: A Case of "Retrogressive Evolution"? International Urogynecology Journal, 27, 831-837. https://doi.org/10.1007/s00192-015-2919-y

[24] Washington, B., Raker, Ch., Kabeja, G., Kay, A. and Hampton, B. (2015) Demographic and Delivery Characteristics Associated with Obstetric Fistula in Kigali, Rwanda. IJGO, 129, 34-37.

[25] Raassen, T., Ngongo, C. and Mahendeka, M. (2014) Iatrogenic Genitourinary Fistula: An 18-Year Retrospective Review of 805 Injuries. International Urogynecology Journal, 25, 1699-1706. https://doi.org/10.1007/s00192-014-2445-3

[26] McCord, C., Mbaruku, G., Pereira, C., Nzabuhakwa, C. and Bergstrom, S. (2009/2014) The Quality of Emergency Obstetrical Surgery by Assistant Medical Officers in Tanzanian District Hospitals. Health Affairs (Millwood), 28, w876-w885. https://doi.org/10.1377/hlthaff.28.5.w876

[27] Waaldijk, K. (2008) Obstetric Fistula Surgery, Art and Science: Comprehensive Manual for Trainees, Training Manual, Cohort Analysis in 2,500 Consecutive 
vvf/rvfpatients, @keeswaaldijk MD PhD, Babbar Ruga Fistula Teaching Hospital, Katsina, Nigeria.

[28] Loposso, M.N., Ndundu, J., DeWin, G., Ost, D., Punga, A.M. and De Ridder, D. (2015) Obstetric Fistula in a District Hospital in DR Congo: Fistula Still Occur Despite Access to Caesarean Section. Neurourology and Urodynamics, 34, 434-437. https://doi.org/10.1002/nau.22601

[29] Results for the 25 to 49 Age Group: The survey tested 6,072 women and 4,209 men in this age group from every administrative region of Tanzania for HIV infection. The survey found that 7.5 percent of women were HIV positive, which was significantly higher than the 5.2 percentage rate for men.

https://en.wikipedia.org/wiki/HIV/AIDS_in_Tanzania

[30] Women are heavily burdened by HIV in Tanzania; 690,000 women aged 15 and over are living with HIV. According to the 2011-12 Tanzania HIV/AIDS and Malaria Indicator Survey, HIV prevalence for women was $6.2 \%$, compared to $3.8 \%$ for men. Women aged 23 - 24 were also twice as likely to be living with HIV, than men of the same age. HIV prevalence among women ranged from $1 \%$ among those aged 15 - 19 to $10 \%$ among women aged $45-49$.

www.avert.org/professionals/hiv-around-world/sub-saharan-africa/tanzania

[31] Holme, A., Breen, M. and MacArthur, C. (2007) Obstetric Fistulae: A Study of Women Managed at the Monze Mission Hospital, Zambia. BJOG, 114, 1010-1017. https://doi.org/10.1111/j.1471-0528.2007.01353.x

[32] Onsrud, M., Sjøveian, S. and Mukwege, D. (2011) Cesarean Delivery Related Fistulae in the Democratic Republic of Congo. International Journal of Gynecology \& Obstetrics, 114, 10-14. https://doi.org/10.1016/j.ijgo.2011.01.018

[33] http://www.endfistula.org/news/we-have-moral-obligation-complete-unfinished-ag enda-eradicating-fistula

[34] https://globalhealthtrainingcentre.tghn.org/obststric-fistula/obstetric-fistular-refere nces/

Submit or recommend next manuscript to SCIRP and we will provide best service for you:

Accepting pre-submission inquiries through Email, Facebook, LinkedIn, Twitter, etc. A wide selection of journals (inclusive of 9 subjects, more than 200 journals)

Providing 24-hour high-quality service

User-friendly online submission system

Fair and swift peer-review system

Efficient typesetting and proofreading procedure

Display of the result of downloads and visits, as well as the number of cited articles

Maximum dissemination of your research work

Submit your manuscript at: http://papersubmission.scirp.org/

Or contact ojog@scirp.org 